\title{
Effects and cost of implementing a gender-sensitive reproductive health program in Bolivia
}

\author{
Erica Palenque \\ Lizzy Montano \\ Ricardo Vernon \\ Population Council \\ Fernando Gonzales Salguero \\ Population Council \\ Patricia Riveros \\ Population Council
}

See next page for additional authors

Follow this and additional works at: https://knowledgecommons.popcouncil.org/departments_sbsr-rh

Part of the Demography, Population, and Ecology Commons, Health Services Research Commons, and the International Public Health Commons

How does access to this work benefit you? Let us know!

\section{Recommended Citation}

Palenque, Erica, Lizzy Montano, Ricardo Vernon, Fernando Gonzales Salguero, Patricia Riveros, and John H. Bratt. 2004. "Effects and cost of implementing a gender-sensitive reproductive health program in Bolivia," FRONTIERS Final Report. Washington, DC: Population Council. 


\section{Authors}

Erica Palenque, Lizzy Montano, Ricardo Vernon, Fernando Gonzales Salguero, Patricia Riveros, and John H. Bratt 


\title{
Effects and Cost of Implementing a Gender- Sensitive Reproductive Health Program
}

\author{
May 2004 \\ Erica Palenque and \\ Lizzy Montaño \\ PROCOSI \\ Ricardo Vernon, \\ Fernando Gonzales, and \\ Patricia Riveros \\ Frontiers in Reproductive Health Program \\ Population Council \\ John Bratt \\ Frontiers in Reproductive Health Program \\ Family Health International
}

This study was funded by the UNITED STATES AGENCY FOR INTERNATIONAL DEVELOPMENT (USAID) under the terms of Cooperative Agreement Number HRN-A-0098-00012-00 and the Population Council Subagreement AI01.11A. The opinions expressed herein are those of the authors and do not necessarily reflect the views of USAID. 


\section{SUMMARY}

The Integral Health Coordination Program (Programa de Coordinación en Salud Integral or PROCOSI) is a network of 24 Bolivian NGOs that coordinates and implements programs to improve the health of the population in need. In 2000, PROCOSI received funding from the USAID Mission in Bolivia to institutionalize a gender perspective in the reproductive and sexual health services offered by the PROCOSI network. Seventeen organizations from the PROCOSI network participated and proposed: 1) to conduct a baseline diagnostic study of the degree to which participating organizations had incorporated gender into their administrative and service delivery policies; 2) to identify problematic areas, develop action plans and implement activities to improve the problems identified based on the baseline study; and 3) to conduct an endline evaluation to see the degree to which the activities had achieved the objectives. The baseline and endline studies were conducted with the International Planned Parenthood Federation's (IPPF) methodology and technical assistance.

PROCOSI and the Population Council's Frontiers in Reproductive Health Program (FRONTIERS) took advantage of this opportunity to evaluate the effects that interventions had on clinic clients and their partners, and to estimate the costs of incorporating a gender perspective into service delivery. FRONTIERS selected 10 clinics run by nine organizations participating in PROCOSI's Gender Program and in each carried out: 1) exit interviews of clients after their visits to the clinic, before and after the gender interventions; 2) a follow-up of these same women in their households three months after the exit interview; 3 ) a household survey of a sample of the women's partners; 4) an analysis of service statistics; 5) a study of the costs of incorporating a gender perspective into service delivery; and 6) a qualitative follow-up study of changes that took place in participating organizations with monthly visits to each clinic.

The project aimed to answer four questions:

1) Can health organizations operationalize a gender perspective?

PROCOSI adapted the methodology proposed by IPPF to design an action plan based on evidence derived from the baseline evaluation of each organization. The results showed that participating organizations effectively implemented two-thirds of proposed actions and an additional 20 percent were in the process of being implemented when the project ended. These actions included changes in infrastructure, training of providers, modification of policies and several others. Qualitative studies showed that workers of participating organizations appropriated the central concepts of gender and used them at work and in their personal lives. User interviews showed modest changes in the practices of service providers, such as more respectful treatment of users, a greater systematic screening of their needs for services, a greater use of didactic material in their explanations to users, a greater effort to involve men, and an increase in the delivery of services requested by clients. As a result, the clients' satisfaction with services increased.

2) Does the incorporation of a gender perspective have a positive effect on the health and well being of the users and on their relationships with their partners? 
The unmet need for anti-tetanus shots among pregnant women and the unmet need for contraceptive services among non-pregnant women were used as proxy variables to evaluate the impact of the interventions on users' health. In the first case, no significant differences were found. However, the proportion of married women of fertile age who did not want a pregnancy in the following two years or did not want to have more children, and who were not using a contraceptive method although they would like to be using one, decreased by nearly 35 percent throughout the duration of the project.

In order to evaluate the changes in partner dynamics, an array of questions were asked related to communication with their partner, perception of gender roles, capacity for decision-making with regard to family resources, and the incidence of gender violence. The results showed that more women spoke to their partners about how many children to have and fewer women thought they had to ask permission from their partners to use contraceptive methods. There was also a greater number of women who felt they could refuse to have sexual intercourse when they did not want to, and also more women who thought that their partners were interested in them enjoying their sexual life. The perception that there are situations in which a man can legitimately beat his partner also decreased.

3) Does this have an effect on the demand for sexual and reproductive health services?

No evidence was found in this project that changes in the perspective with which services were delivered had any effect on the demand for reproductive and sexual health services.

4) Which would be the cost of incorporating a gender perspective into the delivery of reproductive health services?

In this project, the average cost (including both financial and non-financial costs) of adopting a gender perspective among the nine NGOs studied was US\$23,148. Total costs varied substantially across the nine NGOs, reflecting the different mix and intensity of interventions that were implemented. PROCOSI provided cash and technical assistance that accounted for approximately half of this average total cost, while the other half was borne by the NGOs themselves (mainly in the form of personnel). Given the competing demands for program resources, managers must decide whether the impact of the gender interventions was worth the cost of the resources used to achieve it. 


\section{TABLE OF CONTENTS}

SUMMARY

TABLE OF CONTENTS $\quad$ iii

LIST OF TABLES AND GRAPHS v

ACKNOWLEDGMENTS Vii

$\begin{array}{lll}\text { I INTRODUCTION } & 1\end{array}$

II CONCEPTUAL FRAMEWORK 2

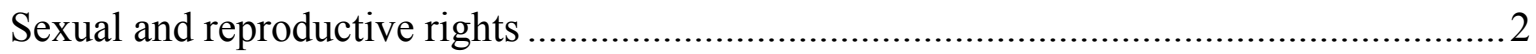

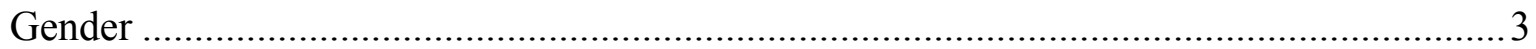

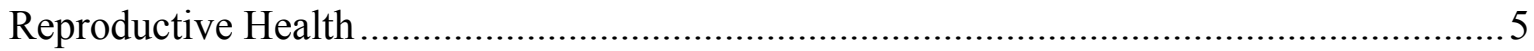

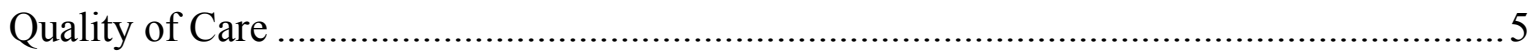

$\begin{array}{lll}\text { iii } & \text { PROBLEM STATEMENT } & 7\end{array}$

iv INTERVENTIONS IMPLEMENTED BY PROCOSI $\quad 8$

$\begin{array}{lll}\mathrm{V} \text { OBJECTIVES } & 10\end{array}$

$\begin{array}{ll}\text { vi METHODOLGY } & 11\end{array}$

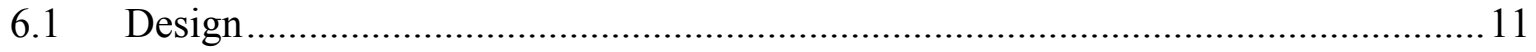

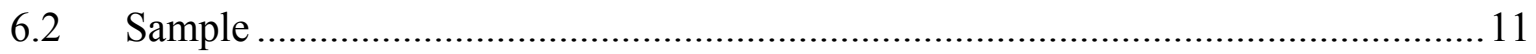

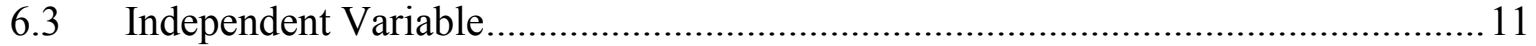

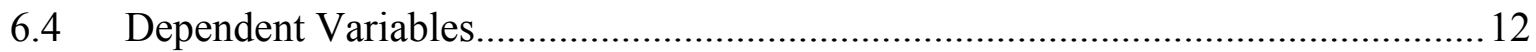

6.5 Sources of Information and Sample Sizes ...................................................... 12

\begin{tabular}{ll} 
vii & RESULTS \\
\hline
\end{tabular}

7.1 Degree to which Participating Clinics Incorporated a Gender Dimension into

Service Delivery from a Quality of Care Perspective ............................................... 17

7.1.1 Compliance with action plans and changes in infrastructure 17

7.1.2 Changes in the perceptions of program actors 21

$\begin{array}{ll}\text { 7.1.3 Changes in providers' practices } & 23\end{array}$

7.1.4 User changes in the perception of and satisfaction with service quality and convenience. 25

7.2 Impact of the Interventions on Unmet Need for Services and Partner Dynamics.... 30

7.2.1 Changes in unmet need for contraception 30

$\begin{array}{lll}\text { 7.2.2 Changes in partner dynamics } & 34\end{array}$

7.3 Changes in Demand for Services ................................................................. 43

Effects and Cost of Implementing a Gender-Sensitive Reproductive Health Program 
7.4 Cost of Introducing a Gender Perspective...................................................... 47

viii CONCLUSIONS AND RECOMMENDATIONS 50

$\begin{array}{lll}\text { ix } & \text { REFERENCES } & 53\end{array}$

$\begin{array}{lll}X & \text { APPENDICES } & 54\end{array}$

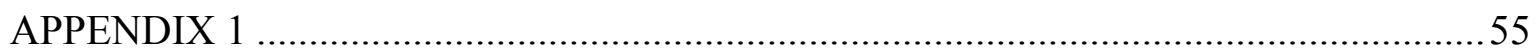

List of Organizations Participating in PROCOSI's Gender Program and FRONTIERS

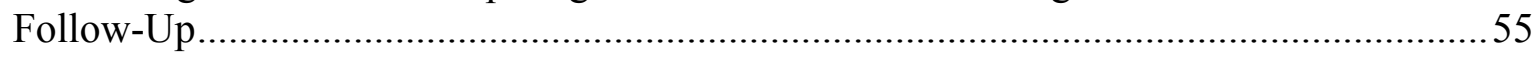

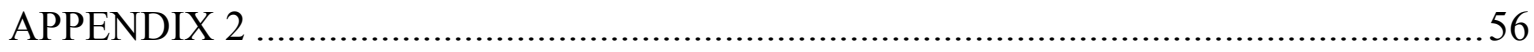

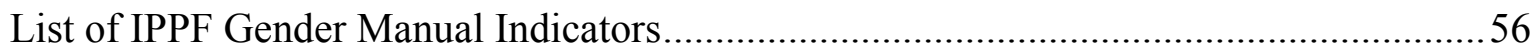

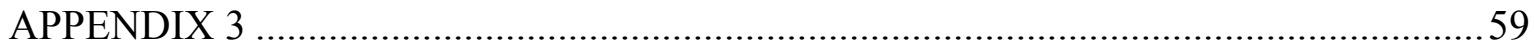

Workshops Organized by the Gender Program ..........................................................59

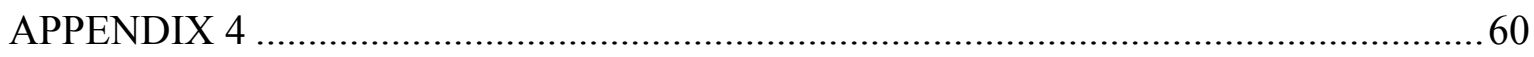

Geographic distribution of the sample and type of management of participating clinics ... 60 


\section{LIST OF TABLES AND GRAPHS}

TABLE 1: Instruments used and number of cases ................................................... 13

TABLE 2: Characteristics of women interviewed in exit survey ................................. 15

TABLE 3: Mean number of actions proposed by the nine participant NGOs and proportion

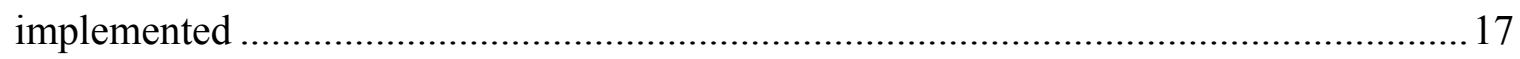

TABLE 4: Examples of actions implemented to improve quality of care .................... 18

TABLE 5: Partner dynamics subjects explored by the provider ..................................25

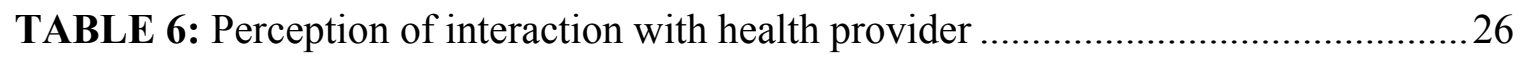

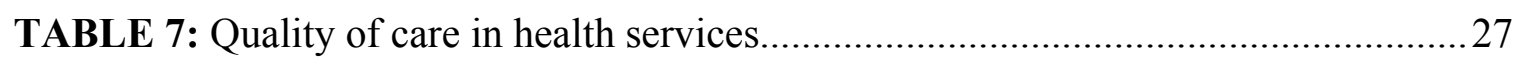

TABLE 8: Main reasons for visiting the clinic and result of the visit..........................28

TABLE 9: Characteristics of contraceptive services.............................................29

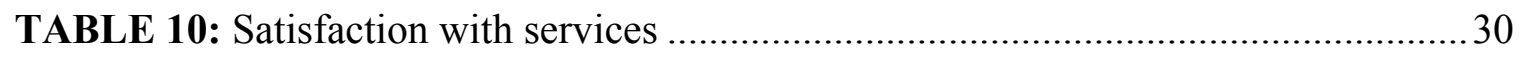

TABLE 11: Number of visits to health outlet in a three month period .......................... 31

TABLE 12: Degree to which providers screened for health service needs..................... 32

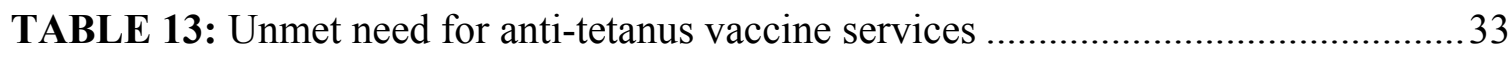

TABLE 14: Unmet need for family planning services............................................ 34

TABLE 15: Decision-making and management of family income ….......................... 36

TABLE 16: Communication between women and their partners on family planning and

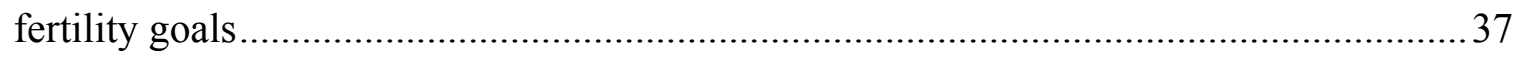

TABLE 17: Perception of the control men have over women by sex and survey............ 39

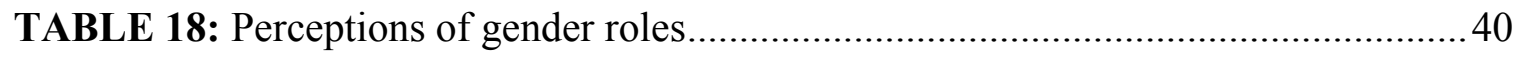

TABLE 19: Perceptions on rights and partner communication on sexuality ................. 42

TABLE 20: Perception of gender-based violence ................................................ 43

TABLE 21: Comparison of private and public clinics' services ................................45

TABLE 22: Total cost of the implementation of gender projects, by NGO ................. 48 
TABLE 23: Contributions from the executive secretariat of PROCOSI........................48

TABLE 24: Total NGO costs of gender projects (US\$) ........................................ 49

GRAPH 1: Detection of Needs by Health Providers.................................................24

GRAPH 2: Visits for injection method (new and continuous) .....................................46

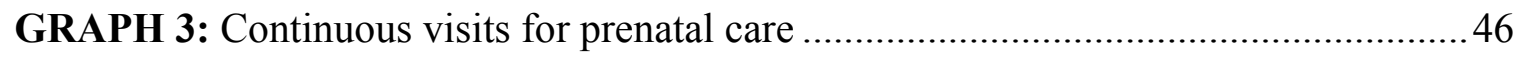




\section{ACKNOWLEDGMENTS}

Horizons Program: Julie Pulerwitz

Data Processing: Fernando Mollinedo V. 


\section{INTRODUCTION}

The Programa de Coordinación en Salud Integral (PROCOSI) is a network of 24 Bolivian NGOs that coordinate and implement programs to improve the health of the population in need. Seventeen affiliated organizations participate in its Reproductive Health Program, which covers close to 100,000 women of reproductive age through its own clinics or through clinics associated with the Ministry of Health that receive technical and financial assistance from these organizations. These organizations also have community programs in which institutional staff and health volunteers participate.

In 2000, PROCOSI received funding from the USAID Mission in Bolivia to institutionalize a gender perspective in sexual and reproductive health services delivered by the PROCOSI network. A total of 17 PROCOSI network organizations participated in a Gender Program and proposed to: 1) do a baseline evaluation of the degree to which organization participants had incorporated gender in their internal policies and delivery of services; 2) identify problem areas, develop action plans and implement activities to improve problems identified based on this diagnosis; and 3) do an endline evaluation to see the degree to which the activities conducted had achieved the objectives. Pre and post-testing was carried out according to the International Planned Parenthood Federation (IPPF) methodology and with their technical assistance.

USAID's Interagency Gender Working Group in Washington, DC considered the PROCOSI Gender Program a good opportunity to evaluate the effects of these kind of interventions on clinic clients and their partners, and to estimate the costs of incorporating a gender perspective into service delivery. USAID Washington thus gave the Population Council funding to undertake operations research to evaluate these aspects of the program.

With this funding, the Frontiers in Reproductive Health Program (FRONTIERS) selected 10 clinics run by nine participating organizations of the PROCOSI Gender Program. Each organization or clinic conducted studies to evaluate the degree to which interventions were implemented, the impact of the Gender Program interventions on their clients and their partners, and the cost of implementing the program.

This report presents the results observed in the PROCOSI Gender Program in 10 clinics belonging to the nine organizations included in the FRONTIERS sample study. 


\section{CONCEPTUAL FRAMEWORK}

Over the last 25 years in Bolivia, but especially during the last decade, there have been four concomitant conceptual movements that have helped to reshape population programs first into family planning programs and then into client-oriented reproductive health programs. Although these four conceptual areas are closely related to each other and are difficult to understand without reference to one another, they have traditionally been discussed separately. Further, when they have been discussed in a unified framework, their relationships have not been made sufficiently clear to help reproductive health service agencies and providers understand how to operationalize these concepts in their routine service delivery activities.

In this section, we will attempt to explain what these four constructs consist of, what the relationships between one and the others are, and how they may be operationalized. The four constructs shaping modern reproductive health programs have been: 1) sexual and reproductive rights; 2) gender; 3) reproductive health; and 4) quality of care. Although the historical development of these concepts has roughly been in reverse order than listed, we believe that they can be more easily understood when presented in the listed order.

\section{Sexual and reproductive rights}

The idea that there are certain inalienable sexual and reproductive rights evolves from the idea that there are certain universal human rights, including the equality between men and women postulated by the United Nations Charter (1945) and the Universal Declaration of Human Rights (1948). Over the years, these rights have been further detailed, strengthened and expanded. Thus, the 1968 Declaration of the World Conference on Human Rights held in Teheran stated that parents have the basic human right to determine in a free and responsible manner the number and spacing of their children, as well as the appropriate education and information to achieve this goal. This basic human right was later extended to couples and individuals in the Bucharest (1974) and Mexico City (1984) Population Conferences.

The 1993 Vienna World Conference on Human Rights advocated the elimination of all forms of discrimination by sex and the eradication of all forms of violence based on gender. The 1994 International Conference on Population and Development established the right to attain the highest standard of sexual and reproductive health, and the Beijing World Conference on Women underlined the importance that women appropriate the means to make free and responsible decisions with respect to their sexuality and reproductive health.

Based on these declarations, several organizations have proposed articles to be included in the United Nations Human Rights Charter, and prepared lists of sexual and reproductive rights. These lists include such elements as the rights to the autonomous exercise of sexuality according to the individuals' preferences; to pleasant, recreational and infection-free sexuality; to sex education; to determine whether to have or not to have sex, when and with

\footnotetext{
${ }^{1}$ This section draws extensively from: CIDEM and FHI. 1999. Para reconocer y respetar las diferencias y derechos en salud sexual y reproductiva. [To recognize and respect sexual and reproductive differences and rights]. La Paz, Bolivia, CIDEM and FHI. This should be considered the basic reference for the section unless otherwise noted.
} 
whom; to voluntary motherhood; to information on contraception; to marry or not; to have children or not; and to decide when and how many to have; to appropriate prenatal, natal, and postnatal services; to legal protection against violence; to adopt and be treated for infertility; to the means to prevent and treat reproductive tract infections; and others. It should be underlined, though, that these proposed articles and lists of rights have not been fully adopted by international conventions, though many of the proposed items would seem not to be controversial, and many are included in service standards and norms.

\section{Gender}

"Gender is a social, cultural and historical construction that assigns certain characteristics and roles to groups of individuals based on their sex.", The gender system is "a set of practices, symbols, representations, norms and social values that societies elaborate from sexual, physiological and anatomical differences,"3 including such aspects as use of language and expressions, clothing, education, work, and others. A central idea of gender as an analytical concept is that it determines the way that men and women relate to each other and the way that power is distributed between them. In general, men have more access to resources than women and greater decision-making power.

The reason gender constructs need to be taken into account by sexual and reproductive health programs is that many of these constructs have a direct impact on women's sexual and reproductive health. Likewise, analyzed through a human rights glass, many of these constructs deny women of their sexual and reproductive rights. This can easily be understood by looking into traditional stereotypes of appropriate or socially accepted gender behavior. For example, it has been documented that the idea that women should remain virgins until marriage leads adolescents in Brazil to engage in anal intercourse, which increases their risk of HIV infection. ${ }^{4}$ Likewise, this construct is contrary to women's rights to pleasant, infection-free sexuality. Sexual and reproductive health programs also need to be aware of gender constructs because they may permeate the behavior of service providers. In this instance, for example, the idea about the importance of virginity could lead service providers to deny contraceptive services to adolescent girls requesting them, even though the job of the service provider should be to protect the health and the sexual and reproductive rights of their clients. $^{5}$

The most concrete proposals taking gender into account in reproductive health programs identify gender-related obstacles for achieving program goals and conduct activities to address these obstacles. Nancy Yinger, ${ }^{6}$ for example, identifies, among others, the following

\footnotetext{
2 CIDEM and FHI. Op. cit.

${ }^{3}$ De Barbieri, Teresita. 1991. Sobre la Categoría de Género. Una introducción teórica metodológica. Direitos Reproductivos, Fundación Carlos Chagas, Sao Paulo.

${ }^{4}$ Weiss, Ellen and G.R. Gupta. 1998. Bridging the Gap. Addressing Gender and Sexuality in HIV Prevention. Washington, D.C., ICRW

${ }^{5}$ How can we know if the behavior of the provider in this example is based on gender considerations and not on other type of social norms? We could, for example, observe the behavior of the same provider when a male adolescent requests for contraceptives.

${ }^{6}$ Yinger, Nancy with A. Peteron and M. Avni. 1999. Mainstreaming Gender in Monitoring and Evaluation. A Practical Approach for Reproductive Health Programming. Draft prepared for the IGWG Okebart, October 6, 1999.
} 
obstacles, and for each suggests activities that may address them and indicators to measure their success:

- Differential access to sources of high quality reproductive health information due to lower literacy among women

- Differential access to sources of high quality reproductive health information and care due to restricted mobility among women

- Women cannot successfully negotiate family planning use because it is culturally inappropriate to discuss sexual issues with providers or partners

- Women cannot successfully negotiate family planning use with their partner due to women's perceptions about their partner's attitude toward family planning

Other examples can be obtained from materials developed to evaluate the degree to which a gender perspective has been incorporated into a reproductive health program. These materials seemingly depart from characteristics that programs should aim to achieve ${ }^{7}$. For example, they ask the client and an observer of clinic conditions (respectively):

- Did the provider talk about ways to incorporate your partner in family planning? About ways to negotiate condom use with him? About your satisfaction with your sexual life? About abuse or maltreatment?

- Were there information, education, and communication (IEC) messages and materials for men?

Clearly, producing this sort of list of gender obstacles or of desirable program characteristics is a necessary first task for considering the gender dimension in reproductive health programs. However, this task needs to be accompanied by other efforts, including training staff so that they can be aware of gender issues and take appropriate action and examining program policies and materials to ensure that appropriate actions for addressing gender obstacles are conducted.

It should be noticed that practices, symbols, representations, norms, and social values related to gender are not the only ones that may act as deterrents to the achievement of individuals' sexual and reproductive rights. Culture, ethnic group, social class, and other factors may also be important obstacles. However, the role of gender considerations in programs is often little understood by service providers, thus requiring greater care.

\footnotetext{
${ }^{7}$ See IPPF/WHR. 2000. Manual to Evaluate the Quality of Care from a Gender Perspective. IPPF/WHR. New York, NY; and Reyes Zapata, Hilda et al. 1999. Un sistema de medición de la calidad de los servicios de salud sexual y reproductiva desde una perspectiva de género [A system to measure the quality of sexual and reproductive health services from a gender perspective] Documento de Trabajo 29. México, D.F., INOPAL III, Population Council.
} 


\section{Reproductive Health}

Contraceptive services were first offered by government and health services out of concern for population growth. Population programs gradually adopted a human rights perspective and began to focus on helping individuals exercise their rights to determine the number and spacing of their children by offering information, freedom to choose and a range of contraceptive services. Over time it became apparent that if programs were to be truly responsive to the needs of their clients, they should recognize that clients have many sexual and reproductive health needs in addition to contraception, and that providers should offer a constellation of services to help their clients to meet these needs.

Reproductive health has been defined as "a state of complete physical, mental, and social well-being and not merely the absence of disease or infirmity, in all matters related to the reproductive system and to its functions and processes. People are able to have a satisfying sex life and they have the capability to reproduce and the freedom to decide if, when, and how often to do so. Men and women have the right to be informed and have access to safe, effective, affordable, and acceptable methods of their choice for the regulation of fertility, as well as access to health care for safe pregnancy and childbirth." ${ }^{8}$ Likewise, it has been underlined that "Sexual Health aims at the enhancement of life and personal relations, and does not consist merely of counseling and care related to reproduction and sexually transmitted diseases." 9

In practical terms, this mandate implies that programs need to offer a set of services that help individuals achieve the basic reproductive rights mentioned above. This has been operationalized by health systems offering the following services: contraception; prenatal, birth, and postnatal care; prevention, diagnosis, and treatment of reproductive tract infections; sex education and counseling; breastfeeding support; and early detection and management for both cervical and breast cancer. It should be noted that the real test of focus on clients' needs is not merely offering or referring them to appropriate services, but rather helping clients identify their needs and providing them the information and services to meet them.

\section{Quality of Care}

Quality of care is an all-encompassing service delivery framework that directs programs to help clients satisfy their needs and expectations at an affordable price. Thus, high quality of care helps clients achieve their sexual and reproductive goals, including determining the number and spacing of children and attaining the highest standard of reproductive health.

Quality of care, by definition, needs to incorporate the gender dimension because gender practices and roles may be obstacles for satisfying clients' needs and expectations. However, quality services also need to take into account other variables including culture, stage of life

\footnotetext{
${ }^{8}$ See Family Care International. Action for the $21^{\text {st }}$ Century. Reproductive Health \& Rights for All. Summary report of recommended actions and reproductive health and rights of the Cairo ICPD programme of action, September 1994. Prepared by María José Alcalá. New York, NY, Family Care International ${ }^{9}$ Ibid
} 
cycle, social class and status, individual preferences, educational level, and sexual practices, among others.

There are three basic elements of quality of care provided by reproductive health programs:

1. Technical capacity, including the knowledge, practices, and resources available to provide medical care according to known and accepted standards and with minimum risk to the client;

2. Treatment of and information given to clients that allows providers to establish mutuallysatisfactory relationships with clients, identify their needs, and give them understandable instructions and materials to help them make decisions and engage in behaviors leading to the satisfaction of their needs. Counseling is central for achieving these goals; and

3. Management, which is the set of norms and practices to allow organizations to continuously transform to fulfill their mission and to better help their clients meet their needs and expectations.

Programs seeking to improve their quality of care need to address these three elements. Clearly, reproductive health programs aiming to introduce a gender perspective also need to do so. Thus, introducing a gender perspective needs to be done within a quality of care framework. 


\section{PROBLEM STATEMENT}

Since the International Population and Development Conference held in Cairo in 1994, educational and health organizations, particularly those that offer reproductive health services, often advocate for the incorporation of a gender perspective in the delivery of services. In 1997, PROCOSI requested its affiliated organizations to work on the subject and periodically assess their progress through a series of indicators designed to measure advances. By 2000, PROCOSI staff reached the conclusion that the progress to date was less than expected, and therefore requested financial support from the USAID mission to carry out a program to help reach the proposed objectives.

Although there are considerable differences of opinion as to what it means to adopt a gender perspective into the delivery of reproductive health services, a central concept is agreed upon by almost everyone: programs should take into account the differences that exist between women's and men's lives, as well as the inequality that may exist in relationships between them, particularly in terms of the exertion of power; decision-making capacity; access to resources; and communication patterns. According to these criteria, in order for a health system to be effective it must consult and seek the participation of women, listen to them, reinforce their capacity to make decisions (particularly those geared towards caring for their health), and respect the decisions they make without prejudices.

Skeptics frequently point out that the concept of adopting a gender perspective is quite vague, and that its meaning should be clearly operationalized in order for health service managers to use it effectively. According to these critics, when an effort is made to operationalize the concept of gender, the results are very similar to those observed when a quality of care framework is used, and therefore it is not clear that clinics can make changes that demonstrate sensitivity to gender issues. Further, they argue that even if the concept of a gender perspective was clearly operationalizable, it has not been empirically proven that the reorganization of services has positive effects on variables such as the number of clients attended, user satisfaction with services or with their use of contraceptive methods, the health and well-being of clinic users, or on relationships with partners. If these positive results are not found, then adopting a gender perspective may use resources that could be better used elsewhere.

This project sought to answer four basic questions: 1) Can health organizations operationalize a gender perspective? 2) If they succeed in doing so, does it have a positive effect on the health and well-being of users, and on their relationships with their partners? 3) Would this strategy have an effect on the demand for sexual and reproductive health services? 4) What would be the costs of adopting a gender perspective into reproductive health service delivery? 


\section{INTERVENTIONS IMPLEMENTED BY PROCOSI}

The following is a brief description of the process and activities implemented by PROCOSI as part of its Gender Program:

Invitation to affiliated organizations: PROCOSI staff visited and invited all the organizations affiliated with its network to participate in its Gender Program. A total of 17 organizations accepted (see Appendix 1) and each placed one or two persons in charge of coordinating project activities.

Selection and adaptation of a framework to operationalize a gender perspective: In order to operationalize the concept of "gender perspective," PROCOSI received technical assistance from the International Planned Parenthood Federation (IPPF), which recommended carrying out the actions proposed in their "Manual to Evaluate Quality of Care from a Gender Perspective." This manual recommends an evaluation of the degree to which organizations have adopted a gender perspective through the use of five different instruments: 1) review of institutional documents; 2) observation of general aspects; 3) observation of counseling and delivery of services to users; 4) exit interviews with clients; and 5) interviews with service providers. The instruments were tested and adapted to PROCOSI's needs so they could take into consideration general and specialized medical services, as well as community programs and projects.

The instruments help evaluate seven organizational areas through 71 indicators that are constructed with the data collected. The areas are: 1) institutional policies and practices (20 indicators); 2) practices of providers (26 indicators); 3) client satisfaction (10 indicators); 4) client comfort (4 indicators); 5) use of gendered language (2 indicators); 6) information, communication and training (6 indicators); and 7) monitoring and evaluation (3 indicators). The complete list of indicators is presented as Appendix 2.

Baseline evaluation and design of action plans: With IPPF's support, PROCOSI trained an evaluation team in each of the 17 participating organizations. The members of the evaluation team, who in some cases were hired and in others were employees of the organizations themselves, applied the instruments and analyzed the results. With assistance from IPPF and FRONTIERS, the members of the evaluation teams attended a workshop to select the most important indicators to improve, taking into account factors such as feasibility to implement actions, time, and resources. In this workshop, the participants' skills for making presentations were also improved. Upon their return, each organization held a workshop with all of their staff to present the more relevant general concepts (e.g. gender, quality of care) as well as the results of the baseline study. Based on this input, participants agreed on the indicators the institution would work on. An action plan was developed for each indicator to be improved, detailing the actions to be implemented, the date on which each action was to be completed, and the person responsible for carrying out each action. 
Implementing action plans: PROCOSI provided each institution with a total of $\$ 3,500$ to implement concrete institutional actions proposed in the action plans. The actions were carried out between March 2002 and June 2003.

Also, PROCOSI provided direct training on 13 subjects that several institutions had included in their action plans. Appendix 3 presents a complete list of the workshops PROCOSI gave on these subjects.

PROCOSI created a package of eight printed materials and distributed them to participating organizations. Four of them were for distribution to clients: a poster on sexual and reproductive rights, a wall calendar, a health card for family planning users, and one for adolescents. The remaining materials were directed toward service providers: a leaflet aimed at reinforcing the same messages that the clients were receiving, a poster on gender, a notepad with printed messages, and a flip-chart on sexuality for use by the service providers. To complement these educational materials in waiting areas, each participating clinic was provided a package of five videos: First Light (Amanecer, JHU/PCS), Speaking with your Partner (Hablemos en Pareja, JHU/PCS), Equity (Equidad, Centro de Promoción de la Mujer Gregoria Apaza), Sexual and Reproductive Rights (Derechos sexuales y reproductivos, IPPF) and Parallel Lives (Vidas paralelas, INNPARES).

Supervision and monitoring: The general coordinator for the Gender Program was in charge of supervising and monitoring project activities. She was also responsible for follow-up on action plans and observed the changes that occurred in situ. The project coordinator for each institution followed-up the progress made on action plan activities and the project coordinator for FRONTIERS/PROCOSI periodically visited to document changes.

Evaluation and presentation of final results: At the end of the project, the evaluating teams for each institution repeated the initial exercise using the same instruments and compiling information on the same indicators. Each team presented results to all personnel at their institution and made a new action plan for the following year's activities. 


\section{OBJECTIVES}

The general objective of this project was to assess the impact and cost of incorporating a gender perspective in reproductive health service delivery.

Specific objectives were the following:

1. To implement a program to provide gender-sensitive sexual and reproductive health services in the PROCOSI network and to document the interventions conducted by service providers to incorporate a gender perspective.

2. To assess the degree to which the program is successful in changing service delivery practices and conditions, and the impact of these on client satisfaction.

3. To evaluate the degree to which clinic users change their knowledge, attitudes, intentions, and behaviors related to reproductive health and partner dynamics.

4. To estimate the impact of incorporating a gender perspective in service delivery on the demand for services.

5. To record the costs of implementing the interventions. 


\section{METHODOLGY}

\subsection{Design}

To estimate the impact of incorporating a gender perspective on the demand for services and the clients' beliefs, attitudes, intentions, and behaviors, this study used a non-experimental design, without a control group, with health service centers and household surveys of users and their partners before and after the Gender Program interventions, as represented in the following figure:

$\begin{array}{lll} & \text { time } & \\ & & \\ -01 & \mathrm{X} & \mathrm{O} 2\end{array}$

where $\mathrm{O} 1$ represents the observations and measurements made before implementing the Gender Program activities (in the period from August to December 2001), X represents the implementation of the gender activities and $\mathrm{O} 2$ represents the measurements made at the end of the gender intervention (in the period from March to July 2003). The observations and measurements made in $\mathrm{O} 1$ and $\mathrm{O} 2$ are detailed in a section following this chapter.

To assess the statistical significance of the observed differences, Student's T test was used in the case of continuous variables. Changes in distributions were assessed by means of the Chi square test.

\subsection{Sample}

To carry out the study, a sample of users was selected in two stages. In the first stage, nine health service organizations were selected from the organizations participating in the PROCOSI Gender Program. This sample was stratified according to the outlet's type of management (outlets with direct management from the $\mathrm{NGO}$, and $\mathrm{MOH}$ outlets that receive assistance from the PROCOSI organizations). In the second stage, 10 clinics from these organizations were selected, of which seven were managed directly by the NGOs and three were $\mathrm{MOH}$ centers. Appendix 1 presents the list of organizations included in the sample and the type of management of the participating clinics. In each selected clinic a sample of observations was established to be made with different instruments.

\subsection{Independent Variable}

The independent variable in this study was the implementation of the PROCOSI Gender Program. 


\subsection{Dependent Variables}

The following were the dependent variables in this study:

- Changes in quality of care and user satisfaction: The indicators used in this section show the degree to which health service providers managed to adopt a gender perspective and improve quality of care. The indicators include variables such as how patients are treated, waiting time, convenience of facilities, review of patient needs, and explanations given to them, among others.

- Changes in unmet need for contraceptive services: Unmet need is defined as the proportion of married, non-pregnant women who do not want to get pregnant in the next two years and are not using contraception although they would like to. This variable is crucial to evaluate the effects of the Gender Program, because the right to choose the number and spacing of children in a free and informed fashion is the only sexual and reproductive right that has been included in all international conferences on population, reproductive health, status of women, and human rights. As one of the main goals of the Gender Program is to increase women's decision-making capacity, particularly on issues relevant to health care, as well as their capacity to exert their reproductive and sexual rights, any gender program in reproductive health service organizations must try to help women meet their fertility goals.

- Changes in partner dynamics: This construct includes different variables related to the relationships between partners and the degree to which they have talked about fertility and timing preferences, about the means to achieve these goals, the degree to which they both seek to make sexual relations more pleasant, the degree to which decisions are shared, and the degree to which services try to change unequal power relations between men and women.

- Changes in demand for reproductive health services: This variable was measured through service statistics. The rationale for including this variable is that good quality of care, including gender-sensitive service delivery, should produce word-of-mouth publicity and increase repeat visits, which would then translate into greater productivity for the participating institution.

- Costs of adapting a gender perspective: The success of this research in proving that adopting a gender perspective brings with it positive changes would make cost an important variable in a manager's decision to introduce the strategy in their health services. This project focused on the costs of starting, replicating, and sustaining intervention activities.

\subsection{Sources of Information and Sample Sizes}

As explained in the introduction to this report, PROCOSI carried out two independent evaluations of its Gender Program, using different procedures. Table 1 lists the different instruments used in the studies carried out by PROCOSI as part of its Gender Program, as well as the number of observations and interviews. The table refers to the universe of 10 clinics and nine organizations that participated in the FRONTIERS follow-up. 


\section{TABLE 1: Instruments used and number of cases}

\begin{tabular}{|c|c|c|c|c|c|}
\hline \multicolumn{6}{|c|}{$\begin{array}{l}\text { Description of instruments used by PROCOSI to assess the effects } \\
\text { total number of cases in the baseline and endline studies }\end{array}$} \\
\hline \multirow[b]{3}{*}{ Instrument } & \multirow[b]{3}{*}{ Technique and application procedure } & \multicolumn{4}{|c|}{ SURVEY } \\
\hline & & \multicolumn{2}{|c|}{ PRE } & \multicolumn{2}{|c|}{ POST } \\
\hline & & $\mathbf{N}$ & $\%$ & $\mathbf{N}$ & $\%$ \\
\hline \multicolumn{6}{|c|}{ Gender Program with IPPF methodology: } \\
\hline Review of documents & $\begin{array}{l}\text { Review of institutional documents, IEC and } \\
\text { training materials }\end{array}$ & 8 & 100 & 8 & 100 \\
\hline $\begin{array}{l}\text { Observation of general } \\
\text { aspects }\end{array}$ & $\begin{array}{l}\text { Observing of privacy and confidentiality } \\
\text { conditions, environment and equipment, } \\
\text { facilities for children, availability, type and } \\
\text { visibility of IEC materials }\end{array}$ & 10 & 100 & 10 & 100 \\
\hline $\begin{array}{l}\text { Observation of } \\
\text { counseling visit }\end{array}$ & $\begin{array}{l}\text { Observation of interaction between provider } \\
\text { and client, information provided, length of } \\
\text { visit, type of treatment provided }\end{array}$ & 400 & 100 & 10 & 100 \\
\hline Client exit interview & $\begin{array}{l}\text { Structured interview of women of fertile age } \\
\text { who have just left completed their visit }\end{array}$ & 1,000 & 100 & 1,000 & 100 \\
\hline Provider interview & $\begin{array}{l}\text { Structured interviews with providers } \\
\text { regarding beliefs, attitudes, intentions and } \\
\text { behaviors of reproductive health services }\end{array}$ & 100 & 100 & 40 & 100 \\
\hline \multicolumn{6}{|c|}{ Effects and Cost Research (FRONTIERS/Population Council) } \\
\hline Informed consent & $\begin{array}{l}\text { Structured interview of all women of fertile } \\
\text { age who have just completed their visit to } \\
\text { ask whether they agree to participate in the } \\
\text { research and be visited at their household } \\
\text { three months after the first interview }\end{array}$ & 1,099 & 100 & 1,062 & 100 \\
\hline Exit interview & $\begin{array}{l}\text { Structured interview in the clinic with all } \\
\text { women of fertile age who agreed to } \\
\text { participate in the research after completing } \\
\text { their visit }\end{array}$ & 1,060 & 100 & 1,062 & 100 \\
\hline $\begin{array}{l}\text { Household interviews of } \\
\text { women }\end{array}$ & $\begin{array}{l}\text { Structured household interview of all clients } \\
\text { who agreed to the interview three months } \\
\text { after their visit to the clinic }\end{array}$ & 923 & 87 & 1,002 & 94 \\
\hline $\begin{array}{l}\text { Household interviews of } \\
\text { women's husbands }\end{array}$ & $\begin{array}{l}\text { Structured interview in household of a } \\
\text { sample of clients' male partners: } 20 \% \text { in the } \\
\text { pre-test and } 30 \% \text { in the post-test }\end{array}$ & 212 & 100 & 318 & 100 \\
\hline $\begin{array}{l}\text { Five different ways to } \\
\text { measure intervention } \\
\text { cost }\end{array}$ & \multicolumn{5}{|c|}{$\begin{array}{l}\text { In-depth interviews with subjects committed to the program in order to } \\
\text { calculate time and investment in kind. The interviews were carried out } \\
\text { during the entire intervention stage }\end{array}$} \\
\hline $\begin{array}{l}\text { Monthly service statistics } \\
\text { of participating clinics }\end{array}$ & \multicolumn{5}{|c|}{$\begin{array}{l}\text { Data collection from the National Health Information System (Sistema } \\
\text { Nacional de Información en Salud - SNIS) on number of visits per month } \\
\text { by type of service }\end{array}$} \\
\hline $\begin{array}{l}\text { Guide for documenting } \\
\text { interventions }\end{array}$ & \multicolumn{5}{|c|}{$\begin{array}{l}\text { In-depth interviews with subjects committed to the program, photographs, } \\
\text { direct observation of changes, and review of documents produced }\end{array}$} \\
\hline
\end{tabular}

SOURCE: Based on the Gender Program's application of instruments and the "Effects and Cost" research 
PROCOSI used five different instruments with funding from the USAID mission in Bolivia and technical assistance from IPPF. NGO employee teams collected data; in these evaluations, the organizations also did their own analyses and wrote their own reports. PROCOSI did not have direct access to the raw data collected during these evaluations, only to the results presented in their reports. For this reason, this report refers only to the results of these evaluations. Nevertheless, the instruments used are explained in detail below because their results were the basis for identifying the problems and developing the Gender Program interventions.

The following instruments were applied as part of the study that PROCOSI conducted with the technical and financial assistance of the FRONTIERS program. These studies were conducted directly by PROCOSI under the guidance of a project coordinator and using rigorous procedures to ensure the quality of the information.

Exit interviews to clinic users: In August 2001, 1,060 women of reproductive age were interviewed after receiving a service at one of the clinics. Participants in each clinic were selected in proportion to the number of users of each clinic; in other words, the sample is proportional to the size of the universe. The interviewers requested the women's consent to participate in the study. Afterwards, they conducted an exit survey for approximately two weeks in each clinic. A total of 1,062 interviews were completed in the endline survey, which was conducted in March 2003. The questionnaire used in this survey focused on the characteristics of the service delivered, the degree to which the providers checked for other reproductive and sexual health needs besides those that motivated the client to go to the clinic, and some aspects of the woman's relationship with her partner.

Table 2 shows the characteristics of women interviewed when leaving their visits. In the pretest, women came in almost equal parts from urban, peri-urban and rural areas, and 60 percent lived in the highlands. Nearly half the women had completed at least some secondary studies, 81 percent spoke Spanish, and 85 percent were married or living with their partner. In the posttest, some small, statistically significant differences were found. These can be attributed to seasonal variations in clinic attendance.

Follow-up of users in their households three months after the exit interview: Women's consent was requested during the exit interviews to conduct a follow-up visit at their households three months later. In the baseline survey conducted in December 2001, 923 women were interviewed ( $87 \%$ of those interviewed in the clinic), while in the endline survey conducted in July 2003, 1,002 interviews were conducted (94\% of those interviewed in the clinic). The questionnaire used at the follow-up interview had a more in-depth focus on aspects reviewed in the exit interviews and assessed knowledge of different reproductive health services, especially contraception. 
TABLE 2: Characteristics of women interviewed in exit survey

\begin{tabular}{|c|c|c|c|c|c|}
\hline \multicolumn{6}{|c|}{$\begin{array}{l}\text { Absolute and percentage distribution of interviewees that participated in the research, by selected } \\
\text { characteristics and survey }\end{array}$} \\
\hline \multirow[b]{3}{*}{ Characteristics } & \multicolumn{4}{|c|}{ SURVEY } & \multirow[b]{3}{*}{ SIG* } \\
\hline & \multicolumn{2}{|c|}{ PRE } & \multicolumn{2}{|c|}{ POST } & \\
\hline & $\mathbf{N}$ & $\%$ & $\mathbf{N}$ & $\%$ & \\
\hline \multicolumn{6}{|l|}{ Reason for clinic visit } \\
\hline Prenatal & 116 & 10.9 & 111 & 10.5 & 0.49 \\
\hline Contraception & 197 & 18.6 & 219 & 20.6 & \\
\hline RHS visit or health of child $<5$ & 747 & 70.5 & 732 & 68.9 & \\
\hline \multicolumn{6}{|l|}{ Area of residence } \\
\hline Urban & 360 & 34.0 & 360 & 33.9 & 1.00 \\
\hline Peri-urban & 340 & 32.1 & 341 & 32.1 & \\
\hline Rural & 360 & 34.0 & 361 & 34.0 & \\
\hline \multicolumn{6}{|l|}{ Region } \\
\hline Highlands & 640 & 60.4 & 641 & 60.4 & 0.99 \\
\hline Valley & 340 & 32.1 & 340 & 32.0 & \\
\hline Plains & 80 & 7.5 & 81 & 7.6 & \\
\hline \multicolumn{6}{|l|}{ Age } \\
\hline $15-19$ & 113 & 10.7 & 93 & 8.8 & 0.48 \\
\hline $20-24$ & 315 & 29.7 & 295 & 27.8 & \\
\hline $25-29$ & 239 & 22.5 & 271 & 25.5 & \\
\hline $30-34$ & 182 & 17.2 & 177 & 16.7 & \\
\hline $35-39$ & 111 & 10.5 & 113 & 10.6 & \\
\hline $40-44$ & 68 & 6.4 & 75 & 7.1 & \\
\hline $45-49$ & 32 & 3.0 & 38 & 3.6 & \\
\hline Mean & \multicolumn{2}{|c|}{27.9} & \multicolumn{2}{|c|}{28.7} & \\
\hline Standard deviation & \multicolumn{2}{|c|}{7.5} & \multicolumn{2}{|c|}{7.5} & \\
\hline \multicolumn{6}{|l|}{ Schooling } \\
\hline $1-3$ & 180 & 17.0 & 141 & 13.3 & $0.00^{*}$ \\
\hline $4-6$ & 184 & 17.4 & 163 & 15.3 & \\
\hline $7-9$ & 150 & 14.2 & 122 & 11.5 & \\
\hline $10--12$ & 399 & 37.7 & 414 & 39.0 & \\
\hline 13 and over & 146 & 13.8 & 196 & 18.4 & \\
\hline Does not remember & 1 & 0.09 & 26 & 2.4 & \\
\hline Mean & \multicolumn{2}{|c|}{8.85} & \multicolumn{2}{|c|}{9.75} & \\
\hline Standard deviation & \multicolumn{2}{|c|}{4.5} & \multicolumn{2}{|c|}{4.4} & \\
\hline \multicolumn{6}{|l|}{ Language } \\
\hline Spanish & 859 & 81.0 & 905 & 85.2 & $0.02^{*}$ \\
\hline Aymará & 16 & 1.5 & 17 & 1.6 & \\
\hline Quechua & 185 & 17.5 & 140 & 13.2 & \\
\hline \multicolumn{6}{|l|}{ Type of relationship to partner } \\
\hline Married / living together & 904 & 85.3 & 874 & 82.3 & $0.00^{*}$ \\
\hline Occasional partner & 27 & 2.5 & 36 & 3.4 & \\
\hline Has no partner & 119 & 11.2 & 132 & 12.4 & \\
\hline Has partner but do not live together & 0 & 0.0 & 20 & 1.9 & \\
\hline Did not answer & 10 & 9.9 & 0 & 0.0 & \\
\hline TOTAL & 1,060 & 100 & 1,062 & 100 & \\
\hline
\end{tabular}

SOURCE: Exit survey for pre- and post-test, applied by the "Effects and Costs" research

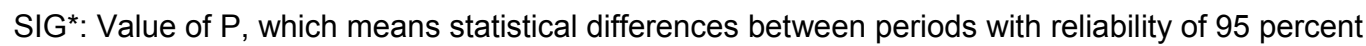

Effects and Cost of Implementing a Gender-Sensitive Reproductive Health Program 
Household interviews of women's partners: Consent was requested from a sample of women during the household interviews to interview their partners. The interviews with men focused on aspects similar to those studied with the women. In the baseline survey, a total of 212 men were interviewed, partners of approximately 20 percent of the women interviewed. In the endline survey, a total of 318 men were interviewed, partners of approximately 30 percent of the women interviewed. In order to select the men to be interviewed, two numbers from one to nine were randomly pre-selected in the baseline and three numbers in the endline. When the number of the last two digits in the questionnaire for the woman (one in every five and one in every three, respectively) ended in the selected digits, an interview was conducted. When the interview could not be done, it was conducted with the following contact.

The men interviewed in the endline survey were 31 years old on average (with a standard deviation of 7.7 years). On average, the men interviewed in the baseline survey had 11 years of schooling (with a standard deviation of 4.3 years) and 10 years (with a standard deviation of 4.2 years) in the endline survey. An interesting fact is that 97 percent of men reported having a formal partnership, a greater proportion than women.

Fieldwork characteristics: In all cases, the interviewing staff was composed of previously trained women with knowledge of the native language and with local residence in the place where the survey was conducted. If the woman being interviewed did not speak Spanish, the interviewers translated the questions directly and wrote down their answers in Spanish on the questionnaire. This happened in approximately 24 percent of cases for exit interviews and in a similar percentage of cases for household interviews. For the exit interviews, three supervisors and 12 interviewers were selected. For the household interviews, four supervisors and 22 interviewers were selected.

Service statistics: Service statistics for participating clinics were entered onto a customized form. The main source of data was the National System for Health Information (SNIS). The statistics gathered included new and continuous users of prenatal services, new and continuous users of contraceptive methods, Pap smears, and users of sexual and reproductive health services. The data was verified during visits made to the outlets.

Program costs: To calculate program costs, five instruments were created that allowed for budgetary information to be entered in different categories and activities: personnel costs, materials, infrastructure, communications, and others. This information was acquired through interviews with the Gender Program coordinators and administrative personnel, who kept the accounting registry for the program.

Documentation of interventions: Throughout the research, periodic visits were made to each organization to obtain information on the personnel involved in the project and to observe the changes that had taken place in the participating clinics. This qualitative information was registered in a notebook kept by the PROCOSI study coordinator (one notebook for each organization was kept). Photographs were also taken of observable changes. 


\section{RESULTS}

The main results of the studies conducted with technical assistance by FRONTIERS are presented in this section. The text also discusses a few results obtained in the studies conducted with technical assistance by IPPF. Results are presented in terms of the main research questions.

\subsection{Degree to which Participating Clinics Incorporated a Gender Dimension into Service Delivery from a Quality of Care Perspective}

This section presents the results of observations and interviews to determine the degree to which the 10 participating clinics implemented actions to incorporate a gender perspective into their practices.

\subsubsection{Compliance with action plans and changes in infrastructure}

Table 3 show that the nine participating organizations on average worked to improve 38 of the 71 indicators proposed by the IPPF manual. The range was from 36 to 40 indicators. In order to improve each selected indicator, participants proposed implementing an average of 15 actions. The majority of improvement actions were proposed in the areas of provider practices (40 actions per organization, on average), institutional policies and practices (25 improvement actions proposed by each organization) and client satisfaction (16 improvement actions per organization, on average).

TABLE 3: Mean number of actions proposed by the nine participant NGOs and proportion implemented

\begin{tabular}{|c|c|c|c|c|c|c|c|c|c|}
\hline \multirow[b]{3}{*}{ Type of indicator } & \multirow{3}{*}{$\begin{array}{l}\text { Total sub- } \\
\text { indicators }\end{array}$} & \multirow{3}{*}{$\begin{array}{c}\text { Mean } \\
\text { number of } \\
\text { sub- } \\
\text { indicators } \\
\text { chosen by } \\
\text { NGO }\end{array}$} & \multirow{3}{*}{$\begin{array}{c}\text { Mean } \\
\text { number of } \\
\text { actions } \\
\text { proposed } \\
\text { by NGO }\end{array}$} & \multicolumn{6}{|c|}{ Degree of compliance with actions } \\
\hline & & & & \multicolumn{2}{|c|}{$\begin{array}{c}\text { Mean number } \\
\text { of actions } \\
\text { abandoned }\end{array}$} & \multicolumn{2}{|c|}{$\begin{array}{c}\text { Mean number } \\
\text { of actions in } \\
\text { process }\end{array}$} & \multicolumn{2}{|c|}{$\begin{array}{c}\text { Mean number } \\
\text { of actions } \\
\text { concluded }\end{array}$} \\
\hline & & & & $\mathbf{N}$ & $\%$ & $\mathbf{N}$ & $\%$ & $\mathbf{N}$ & $\%$ \\
\hline $\begin{array}{l}\text { Institutional Policies } \\
\text { and Practices }\end{array}$ & 20 & 10 & 25 & 8 & 32 & 12 & 48 & 5 & 20 \\
\hline $\begin{array}{l}\text { Practices of } \\
\text { providers }\end{array}$ & 26 & 14 & 40 & 2 & 5 & 3 & 7.5 & 35 & 87.5 \\
\hline Client comfort & 4 & 3 & 12 & 0 & 0 & 0 & 0 & 12 & 100 \\
\hline Client satisfaction & 10 & 4 & 16 & 0 & 0 & 2 & 12.5 & 14 & 87.5 \\
\hline $\begin{array}{l}\text { Non-discriminatory } \\
\text { language }\end{array}$ & 2 & 2 & 3 & 0 & 0 & 0 & 0 & 3 & 100 \\
\hline IEC & 6 & 4 & 12 & 0 & 0 & 0 & 0 & 12 & 100 \\
\hline $\begin{array}{l}\text { Monitoring and } \\
\text { evaluation }\end{array}$ & 3 & 1 & 2 & 0 & 0 & 0 & 0 & 2 & 100 \\
\hline TOTAL & 71 & 38 & 114 & 17 & 14.9 & 22 & 19.2 & 75 & 65.9 \\
\hline
\end{tabular}

SOURCE: Based on the Guide for Documentation of Interventions, "Effects and Costs" research 
TABLE 4: Examples of actions implemented to improve quality of care

\begin{tabular}{|c|c|c|}
\hline INDICATOR & ACTIONS IMPLEMENTED & $\begin{array}{l}\text { Number of } \\
\text { NGOs }\end{array}$ \\
\hline \multirow{2}{*}{$\begin{array}{l}\text { Institutional } \\
\text { Policies and } \\
\text { Practices }\end{array}$} & Reviewed and adapted the institutional mission, vision, guidelines, and regulations & 7 \\
\hline & $\begin{array}{l}\text { Disseminated and implemented organizational guidelines and regulations for all } \\
\text { employees }\end{array}$ & 2 \\
\hline \multirow{9}{*}{$\begin{array}{l}\text { Provider } \\
\text { practices }\end{array}$} & Supervised and applied the practice of calling clients by their names & 9 \\
\hline & Verified that all providers displayed their identification & 9 \\
\hline & Offered talks in waiting rooms with didactic materials, following a schedule & 9 \\
\hline & $\begin{array}{l}\text { Mentioned sexual and reproductive health (SRH) topics, particularly breast exams, PAP } \\
\text { smears and contraception }\end{array}$ & 9 \\
\hline & Presented a SRH subject in an internal meeting at least once a month & 5 \\
\hline & Placed office hours in a visible place with the name of the providers attending in each shift & 9 \\
\hline & Obtained IEC materials on gender to use during patient visits & 9 \\
\hline & Organized evening sexuality, gender, and SRH courses or sessions for the communities & 2 \\
\hline & $\begin{array}{l}\text { Organized fairs on sexuality, gender, and SRH topics alongside community authorities, } \\
\text { colleges and other institutions }\end{array}$ & 8 \\
\hline \multirow{5}{*}{ Client comfort } & $\begin{array}{l}\text { Equipped waiting rooms: replaced old seats, provided water or coffee, placed heaters or } \\
\text { fans, painted walls, opened windows, changed the environment for more functional space }\end{array}$ & 9 \\
\hline & $\begin{array}{l}\text { Built or adapted rooms and open-air parks to entertain and care for clients' children during } \\
\text { visits }\end{array}$ & 9 \\
\hline & $\begin{array}{l}\text { Placed doors in consulting rooms and baskets for depositing clinical histories for the next } \\
\text { patient so nurses would not enter and interrupt the visit, giving audible and visual privacy } \\
\text { to the visit }\end{array}$ & 9 \\
\hline & Installed diaper changing tables in waiting rooms & 9 \\
\hline & Placed signs on walls and doors to orient users & 9 \\
\hline \multirow{3}{*}{$\begin{array}{l}\text { Client } \\
\text { satisfaction }\end{array}$} & Supervised and evaluated efforts to ensure waiting time was not more than 30 minutes & 9 \\
\hline & $\begin{array}{l}\text { Supervised provider-client interactions to ensure client questions were answered in detail, } \\
\text { problems were explained, supplies requested were provided, IEC materials were used }\end{array}$ & 9 \\
\hline & $\begin{array}{l}\text { Evaluated clinic personnel to assess the degree to which they treated clients with respect } \\
\text { and attention }\end{array}$ & 9 \\
\hline \multirow{3}{*}{$\begin{array}{l}\text { Non- } \\
\text { discriminatory } \\
\text { language }\end{array}$} & Observed and supervised the practice of avoiding diminutive language & 9 \\
\hline & Observed and supervised the use of gender-specific language & 9 \\
\hline & Observed and supervised the use of respectful language with clients and staff members & 9 \\
\hline \multirow{4}{*}{ IEC } & $\begin{array}{l}\text { Purchased video equipment to project videos in waiting rooms on sexual and reproductive } \\
\text { rights with a focus on gender }\end{array}$ & 7 \\
\hline & Acquired and created their own IEC material with these messages & 9 \\
\hline & $\begin{array}{l}\text { Posters and signs with gender-related concepts displayed on waiting room and main } \\
\text { consulting room walls }\end{array}$ & 9 \\
\hline & Distributed and explained health cards and pamphlets in consulting and waiting rooms & 9 \\
\hline \multirow{3}{*}{$\begin{array}{l}\text { Monitoring } \\
\text { and evaluation }\end{array}$} & Installed suggestion and complaint boxes in waiting room & 9 \\
\hline & Provided suggestion notebook for staff & 4 \\
\hline & Gender Program coordinators and directors and clinic managers followed-up action plans & 9 \\
\hline
\end{tabular}

SOURCE: Based on the Guide for Documentation of Interventions, "Effects and Costs" research 
Table 3 also shows that by the time the Gender Program ended, nearly 66 percent of the actions proposed had been completed, and 19 percent were in the process of being implemented. The area in which the least degree of compliance was observed was institutional policies and practices, where only 20 percent of proposed actions were finished, and 48 percent were still in process at the end of the project. In all other areas, 87 percent or more actions proposed were implemented. All of the improvement actions related to the comfort of clients; information, education, and communication materials; and training were implemented. Table 4 presents some examples of the actions implemented most frequently by the organizations to improve different indicators.

As mentioned before, the project coordinator visited the participating clinics approximately every five or six weeks to verify and document that these actions took place as a consequence of the gender project. The coordinator observed that some changes went beyond what each organization proposed in its action plans. These changes included greater consciousness on behalf of clinic workers on labor rights, more teamwork, greater emphasis on following rules that guarantee service quality, and use of more gender-inclusive language.

As an example of the vast documentation of the physical changes that took place, following is a sequence of photographs that show the creation of a child-care center. This center is within a clinic and will generate greater demand for reproductive health services, for while the mother is in consultation, her children's psychometric and anthropometric health are evaluated, the results of which are given to mothers when they pick up their children at the center. 


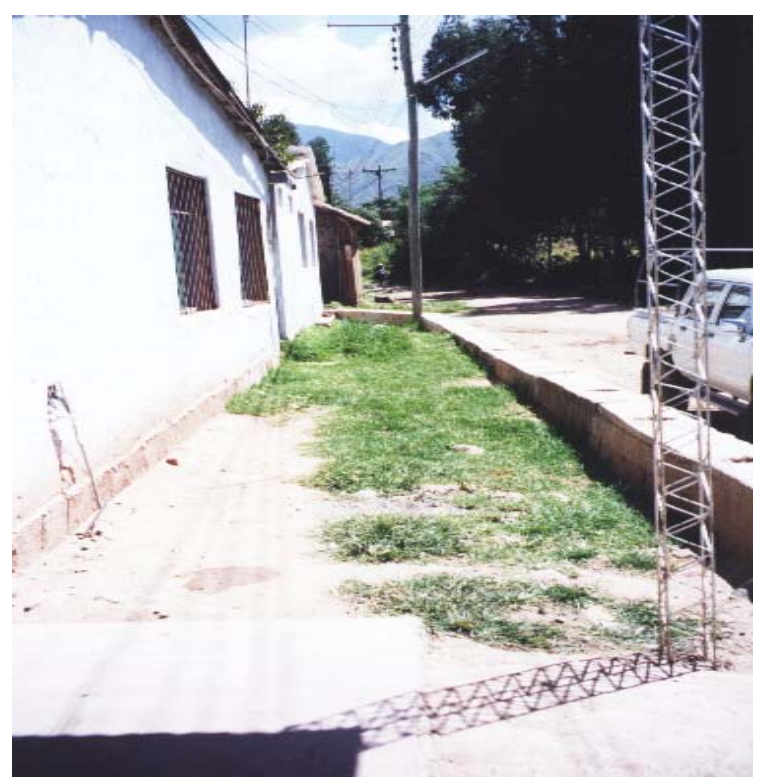

Photo 1: Space at the beginning of the construction

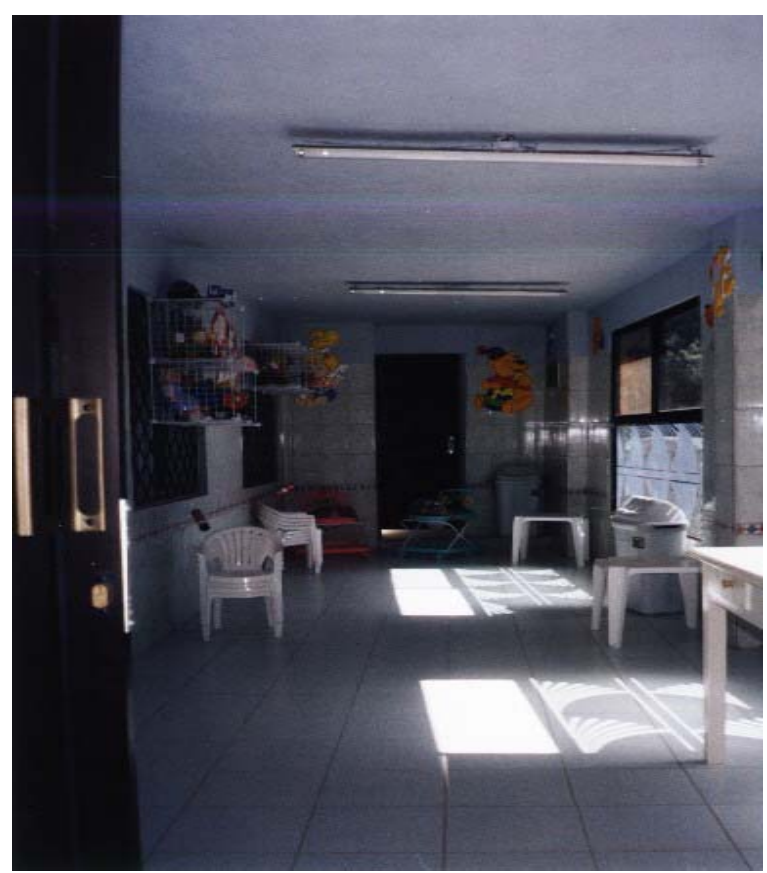

Photo 3: Center completed

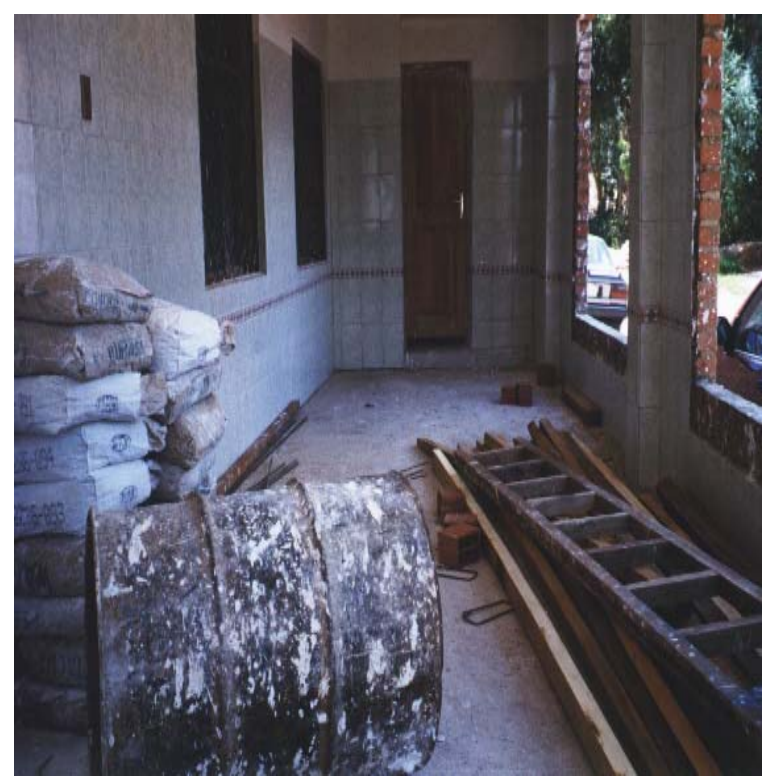

Photo 2: In construction

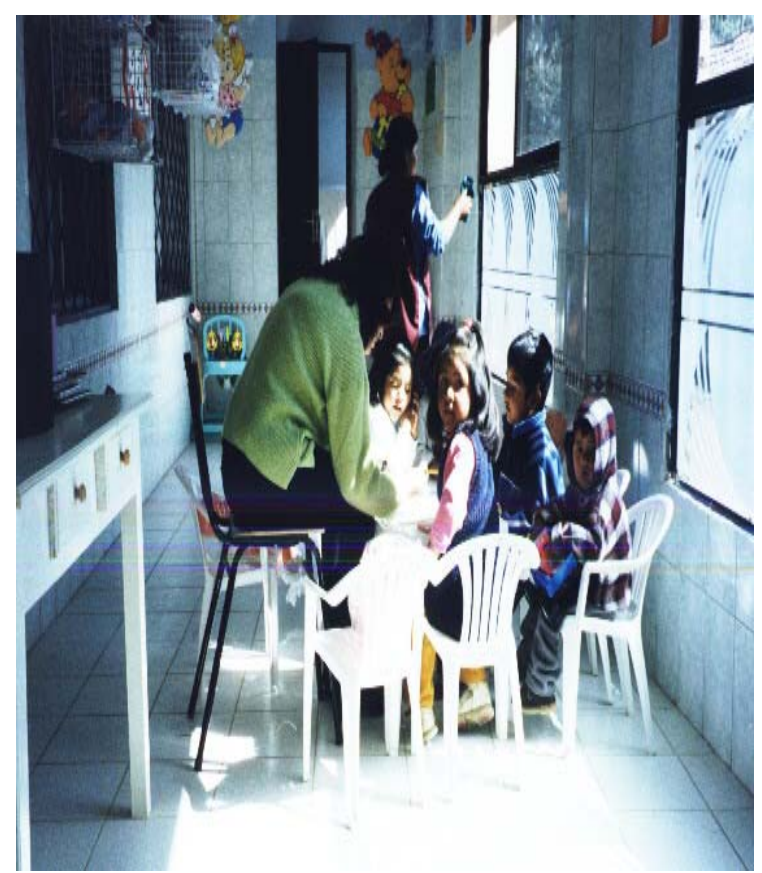

Photo 4: Center in use 


\subsubsection{Changes in the perceptions of program actors}

The interviews by PROCOSI with the technical assistance of IPPF show that by the end of the project, workers from participating NGOs felt they had improved relationships with their supervisors. In four institutions that implemented actions to improve staff relations, an increase was observed in the proportion of providers that felt top managers were receptive to their opinions and suggestions, up seven percentage points from the beginning of the program. At the same time, the proportion of employees who felt motivated to give opinions and suggestions increased by nine percent. Further, in the five organizations that sought to improve teamwork, the proportion that felt the institution had a collective and team environment increased by 20 percent.

The qualitative interviews conducted throughout the project by the FRONTIERS/ PROCOSI coordinator with managers, service providers, and clients also provide information on the changes in worker perceptions in the 10 participating clinics. The "one-to-one" "interviews were held in a private and confidential space in order to collect reliable information from respondents on their thoughts, feelings, and attitudes about the program's implementation process. The main results were the following:

\section{NGO directors}

Two or more interviews were conducted with seven of the nine participating NGO directors. In the beginning, the directors did not have a thorough understanding of what it meant to incorporate a gender perspective into service delivery. They felt that the gender perspective already existed within their institutions, and were expecting a financial contribution to continue programs. Also, at first the implementation of the Gender Program presented a problem for them, as they had to assign greater responsibilities to personnel already occupied with other functions. In subsequent interviews, the managers were more committed and knowledgeable of the changes that were occurring in their staff's behavior. They said they had observed "a positive change in their personnel," "they seem more committed to work and the institution," "they have changed the face of the institution," "we have all learned," and "gender is a change in attitude and commitment."

\section{Project coordinators}

According to the interviews held during the first period of data collection, enthusiasm for "being part of a change" could be perceived among the project coordinators.

In mid-process they showed ambivalence, as the program was seen as "a good experience to improve their lives with regards to their social environment" and "helped get to know the concept of gender in depth," but many also felt "it is too time-demanding to coordinate and carry out activities without monetary reward" despite recognition from

\footnotetext{
${ }^{10}$ Younger, E; S. Wittet, C. Hooks and H. Laser. 2001 - "Guía para el diseño y elaboración de investigaciones cualitativas" (Guide for the design and implementation of qualitative research). Chapter on In-depth Interviews, Page 19, PATH, Seattle, Washington
} 
health providers and seeing the enthusiasm with which people in the municipalities, colleges, and neighborhood councils collaborated.

One of the negative experiences this group had was forming groups of providers and seeing members leave for various reasons (e.g. change in the State administration, internship personnel, ${ }^{11}$ leaving for a better salary). This problem represented "a waste of time and economic resources" and was beyond the control of the participating NGOs, particularly when they were providing technical assistance to clinics administered by the Ministry of Health.

At the end of the project, the project coordinators described the positive effects in terms of changes in their personal lives as well. They commented: "The project has changed my life; now I have more confidence in myself." "I handle my life and my relationship with my partner with greater confidence and without fears." "I have managed to negotiate many activities within the home with my partner." "My relationship has improved."

\section{Staff of participating clinics}

Clinic managers, service providers, and other non-technical personnel, such as doormen and women and cleaning personnel, were interviewed.

At first, Ministry of Health and NGO clinic managers had different attitudes about the gender program. MOH staff were afraid the action plans would not be complied with because of high staff turnover. NGO managers were ready to support the program and foster change. In the beginning, the managers did not understand the reason for the project because they felt that the objectives were already met through periodic evaluations measuring quality of care. Afterward, they recognized positive effects. One commented, "In young and new health providers, changes can be seen." Another observed, "The project has made me change my views and behavior within my job, my home, my surroundings."

Beyond personal changes, directors observed changes in the patient care process and in the coverage of services. One commented, "A certain group of users of the establishment have been allowed to determine their own office hours and we respect it." Another said, "The relationship is not doctor-client, but rather it is all the process from counseling to treatment techniques. It is a whole that is interacting." Another director said, "I think that due to the change in attitude in health providers in this establishment, coverage has increased."

Health care providers also emphasized changes in their personal behaviors and attitudes. "Now that we know our job and women's rights, we are organizing actions to make ourselves respected," a provider commented. A female provider observed, "Male personnel have always treated us as lesser." Another female provider said, "I have learned new things as a woman and should transmit them to the clients that come here.

\footnotetext{
${ }^{11}$ Personal de internado: university students that, through agreements between NGOs and universities, offer services in health establishments for short periods of time; they are the ones with the greatest contact with users in these establishments.
} 
They don't know how to defend themselves from their husbands' violence." As can be seen, the project motivated female personnel to have more solidarity and sensitivity toward clients' problems.

\section{Health establishment users}

Throughout the project, around 60 clinic clients of both sexes were interviewed. At first, the interviewees noticed no changes in services or clinic infrastructure. Later they commented that, "there are quite a few physical changes, a changing table, water fountains and more cleanliness." Another observed, "The television sets pass films on how violence has an influence on health." Female clients commented on changes in quality of care as well, "When I come I am treated more kindly, they make me feel more trust." One client observed, "The doctor speaks to me on violence in society. Before, she only attended my problem." Another said, "The doctor cares about me more now than before."

The men interviewed said, "Here I have learned to share more with my family." Another commented about providers' improved relationships with patients, "The establishment's personnel work with the community like friend with friend, much more than before." Furthermore, men reported that they learned lessons they could apply at home, "It is fun coming to the training sessions, as we play we learn to respect our children and women."

\section{Conclusion}

In conclusion, qualitative interviews showed that the principal actors in the project generally mentioned change in their personal attitudes and lives as the project's main effect. Changes in processes of patient care were mentioned less frequently. At the end of the project, clients who had gone to the clinic for several years could identify changes in both infrastructure and care processes.

\subsubsection{Changes in providers' practices}

Quality of care is defined as care that takes into account the feelings and experiences of people, as well as their gender, cultural, social, and generational specificities, with the aim of helping them solve their sexual and reproductive health problems and satisfying their expectations through respectful treatment and open communication. ${ }^{12}$ PROCOSI, with technical assistance from IPPF, observed visits and interviewed clients as they left the targeted clinics to evaluate changes in provider practices and improvements in quality of care. In general, these observations showed that the organizations that selected concrete indicators to improve were successful in changing specific service provider practices. Pap smear promotion, explanations to patients during the pelvic exam, explanations of the recommended treatment, use of didactic material to reinforce explanations, and exploration of aspects related to the sexual health of clients were observed to increase between 22 and 27 percentage points from pre- to post-test. Behaviors such as greeting the clients, introducing the client to the provider, and

12 IPPF/BOLIVIA Manual para evaluar la calidad de atención desde una Perspectiva de Género [Manual to Evaluate the Quality of Care from a Gender Perspective]. Page16. Bolivia, January 2000. 
promoting breast self-examinations improved between 31 and 39 percentage points. Out of the 15 practices analyzed, the least change was observed between the pre-test and the post-test $(16 \%)$ on providers responding to questions and clarifying patient's doubts.

Behaviors such as addressing clients by their names, waiting on them without interruptions, and promoting condom dual protection improved by over 50 percentage points. The only behavior that did not improve and actually became worse was the use of diminutives when referring to clients, a behavior which apparently health providers feel is proof of affection and care.

In terms of the theoretical framework for this research, there are two essential practices that service providers must perform in adopting a gender perspective. The first is the detection of unmet service needs, and the second is the exploration of the relationship that the woman has with her partner. The first of these practices seeks to strengthen the capacity of women to make decisions to protect their own health. The second is directed toward helping women negotiate with their partners for use of services, facilitate joint decision-making, and maintain more equitable relationships with man.

In the exit interview, several questions were asked in order to see whether the providers had asked or spoken to the woman to determine whether she needed and wanted other services such as contraception, HIV and STI prevention counseling, and cervical and breast cancer prevention information. Graph 1 shows that throughout the project service providers systematically reviewed their patients' sexual and reproductive health needs and motivated them to use the services they needed. Despite this increase, it is notable that the need for any of the services listed was explored with less than half the women interviewed.

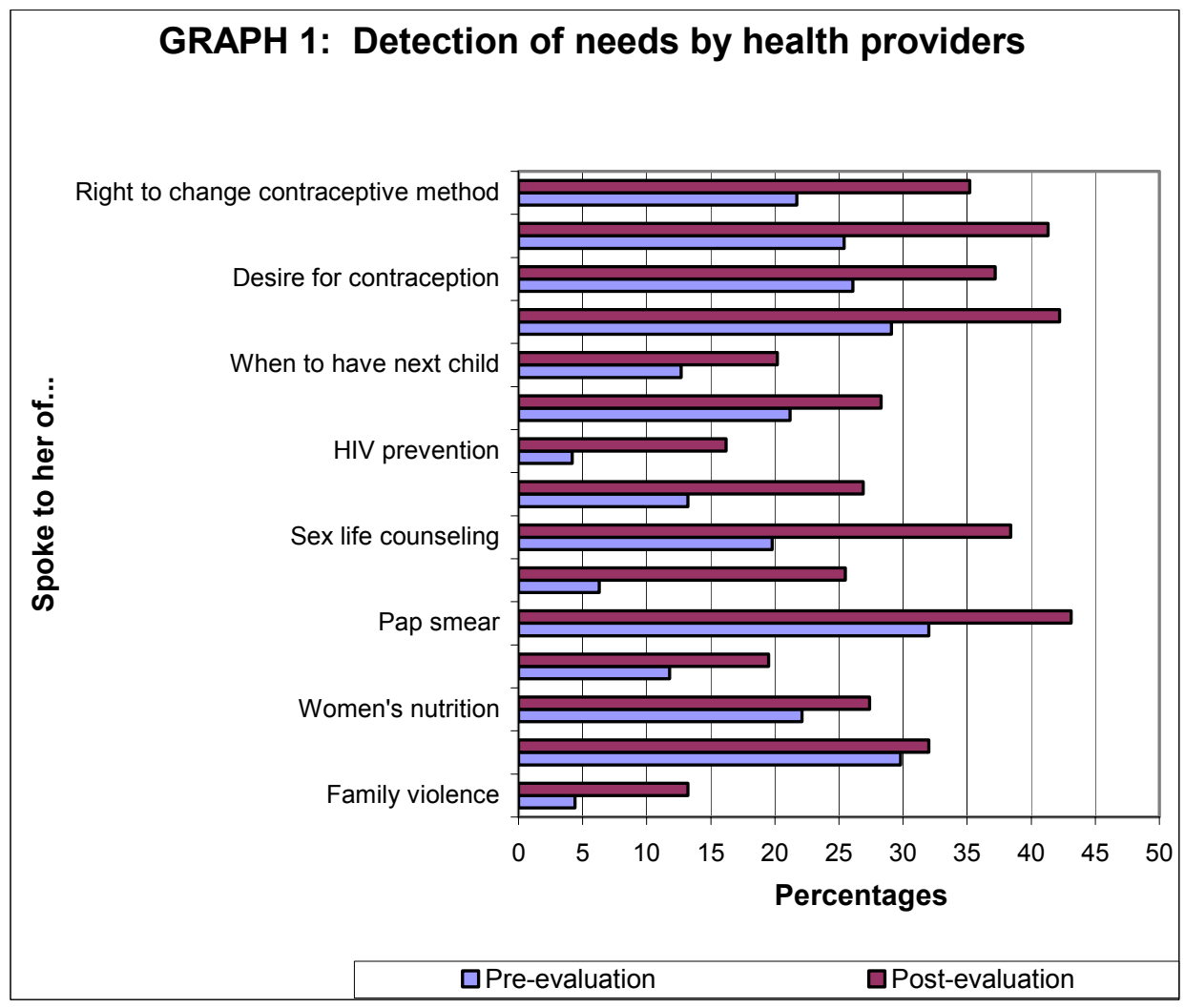

Effects and Cost of Implementing a "Gender-Sensitive" Reproductive Health Program 
Table 5 shows the degree to which service providers explored the woman's relationship with her partner and sought to modify aspects of this relationship. Throughout the project there was an increase in the proportion of women asked by the health provider about communication with their partners on family planning, as well as the proportion who were advised to speak to their partners on this subject. The proportion of providers who gave women ideas about how to approach the subject with their partners and recommended that they bring them to the clinic for more information also increased. However, even in these cases these behaviors occurred only in slightly more than one fourth of the interactions between clients and service providers.

\section{TABLE 5: Partner dynamics subjects explored by the provider}

\begin{tabular}{|c|c|c|c|c|c|}
\hline \multicolumn{6}{|c|}{ Women who reported that the service provider explored or recommended actions for } \\
\hline \multirow[b]{3}{*}{ VARIABLES } & \multicolumn{4}{|c|}{ SURVEY } & \multirow[b]{3}{*}{ SIG* } \\
\hline & \multicolumn{2}{|c|}{ PRE (N =931) } & \multicolumn{2}{|c|}{ POST $(\mathrm{N}=930)$} & \\
\hline & $\mathbf{N}$ & $\%$ & $\mathbf{N}$ & $\%$ & \\
\hline $\begin{array}{l}\text { Provider asked if she spoke about family planning with } \\
\text { partner }\end{array}$ & 245 & 26.3 & 375 & 40.3 & $0.00^{*}$ \\
\hline Provider suggested she speak to partner of these subjects & 203 & 21.8 & 323 & 34.7 & $0.00^{*}$ \\
\hline $\begin{array}{l}\text { Provider suggested how to share this information with } \\
\text { partner }\end{array}$ & 138 & 14.8 & 268 & 28.8 & $0.00^{*}$ \\
\hline Provider asked that she bring partner to health outlet & 128 & 13.7 & 222 & 23.8 & $0.00^{*}$ \\
\hline $\begin{array}{l}\text { Provider asked if she wanted to bring her partner to health } \\
\text { outlet }\end{array}$ & 127 & 13.6 & 263 & 28.2 & $0.00^{*}$ \\
\hline
\end{tabular}

SOURCE: Exit interview, pre- and post-intervention applied by the "Effects and Costs" research

$S^{*} G^{*}$ : Value of $P$, which means a statistical difference between periods with a confidence level of 95 percent

\subsubsection{User changes in the perception of and satisfaction with service quality and convenience.}

Table 6 shows that in the endline exit survey, interviewed clients reported that providers called them by their names, gave clear explanations, provided IEC materials, and had time to answer questions more frequently than in the baseline interview. In almost all cases, the differences observed were statistically significant.

Table 6 also explores changes in clients' perceptions of their relationships with service providers. In general, a smaller proportion of women reported having been treated in a non-amiable or less respectful manner, having felt uncomfortable in their interactions with the provider, or having felt uncomfortable when speaking of certain subjects with the provider. A greater proportion of users in the endline survey also thought the clinic environment was comfortable. However, in the endline survey there was also a significantly larger proportion of users who felt a lack of privacy and that they could be seen by other people during their visit. 
TABLE 6: Perception of interaction with health provider

\begin{tabular}{|c|c|c|c|c|c|}
\hline \multirow[b]{3}{*}{ VARIABLES } & \multicolumn{4}{|c|}{ SURVEY } & \multirow[b]{3}{*}{ SIG* } \\
\hline & \multicolumn{2}{|c|}{ PRE $(\mathrm{N}=1,060)$} & \multicolumn{2}{|c|}{$\begin{array}{c}\text { POST } \\
(\mathrm{N}=1,062)\end{array}$} & \\
\hline & $\mathbf{N}$ & $\%$ & $\mathbf{N}$ & $\%$ & \\
\hline Non-amiable treatment & 35 & 3.3 & 29 & 2.7 & 0.53 \\
\hline Felt she was not treated with respect & 21 & 2.0 & 17 & 1.6 & 0.80 \\
\hline \multicolumn{6}{|l|}{$\begin{array}{l}\text { Of those that interacted with the following agents, } \\
\text { proportion that considered the treatment regular or bad: }\end{array}$} \\
\hline Receptionist & 39 & 3.7 & 68 & 6.4 & $0.00^{*}$ \\
\hline Nurse & 71 & 6.7 & 40 & 3.8 & $0.00^{*}$ \\
\hline Doctor & 53 & 5.0 & 40 & 3.8 & 0.16 \\
\hline Felt uncomfortable with the interaction & 88 & 8.3 & 62 & 5.8 & $0.02^{*}$ \\
\hline Felt others could hear her during the visit & 166 & 15.7 & 180 & 16.9 & 0.42 \\
\hline Felt others could see her during the visit & 179 & 16.9 & 228 & 21.5 & $0.00^{*}$ \\
\hline Felt the space was comfortable & 986 & 93.1 & 1005 & 94.6 & 0.12 \\
\hline Called by her name & 770 & 72.7 & 922 & 86.8 & $0.00^{*}$ \\
\hline Felt explanations given were easy to understand & 988 & 93.2 & 1005 & 94.6 & 0.16 \\
\hline Provider used visual aids in his/her explanations & 178 & 16.8 & 346 & 32.6 & $0.00^{*}$ \\
\hline Provider informed her she had the right to ask questions & 215 & 20.3 & 508 & 47.8 & $0.00^{*}$ \\
\hline Had time to ask questions & 825 & 77.8 & 885 & 83.3 & $0.00^{*}$ \\
\hline Asked questions & 780 & 73.6 & 851 & 80.1 & $0.00^{*}$ \\
\hline Felt uncomfortable speaking of some subjects & 43 & 4.1 & 34 & 3.2 & 0.29 \\
\hline
\end{tabular}

SOURCE: Exit interview, pre- and post-intervention applied by the "Effects and Costs" research

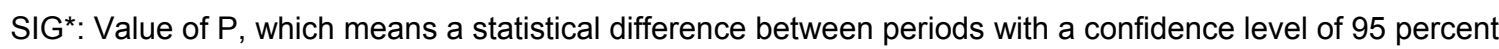

Table 7 shows that the waiting time for visits also decreased slightly, and the proportion of women who received education or information in the waiting room increased slightly. Although the perception that the schedule was convenient did not improve significantly, this is probably due to the fact that the proportion that considers it convenient was already very high at the baseline.

Similar results were found when comparing pre and post-tests conducted with IPPF's assistance. Clinics that sought to improve specific indicators related to client satisfaction and comfort did so modestly (between six and 11 percentage points), improving aspects such as clients' perception of the office hour convenience, friendliness of treatment by clinic staff, educational activities available, and general satisfaction with services received. 
TABLE 7: Quality of care in health services

\begin{tabular}{|c|c|c|c|c|c|}
\hline \multicolumn{6}{|l|}{ Women's perceptions of various quality of care variables } \\
\hline \multirow[b]{3}{*}{ VARIABLES } & \multicolumn{4}{|c|}{ SURVEY } & \multirow[b]{3}{*}{ SIG* } \\
\hline & \multicolumn{2}{|c|}{ PRE $(\mathrm{N}=1,060)$} & \multicolumn{2}{|c|}{$\begin{array}{c}\text { POST } \\
(\mathrm{N}=1,062)\end{array}$} & \\
\hline & $\mathbf{N}$ & $\%$ & $\mathbf{N}$ & $\%$ & \\
\hline \multicolumn{6}{|l|}{ Waiting time for visit: } \\
\hline \multicolumn{6}{|l|}{ Less than 30 minutes } \\
\hline 30 minutes to 1 hour & $\begin{array}{l}496 \\
288\end{array}$ & $\begin{array}{l}46.8 \\
27.2\end{array}$ & $\begin{array}{l}523 \\
326\end{array}$ & $\begin{array}{l}49.2 \\
30.7\end{array}$ & 0.00 \\
\hline Over one hour & 265 & 25.0 & 211 & 19.9 & \\
\hline Did not answer/NA & 11 & 1.0 & 2 & 0.2 & \\
\hline $\begin{array}{l}\text { Educational or informational activities provided during } \\
\text { wait }\end{array}$ & 181 & 17.1 & 338 & 31.8 & $0.00^{*}$ \\
\hline \multicolumn{6}{|l|}{ Convenience: } \\
\hline Considers office hours convenient & 979 & 92.4 & 976 & 91.9 & 0.69 \\
\hline $\begin{array}{l}\text { Knows a place where they can leave their children during } \\
\text { their visit }\end{array}$ & 7 & 0.7 & 12 & 1.1 & 0.25 \\
\hline
\end{tabular}

SOURCE: Exit interview, pre- and post-intervention applied by the "Effects and Costs" research

SIG*: Value of $\mathrm{P}$, which means a statistical difference between periods with a confidence level of 95 percent

Table 8 shows the main reason why the women interviewed went to the clinic and whether they received the treatment they wanted, a central aspect of quality of care. The table shows that over a third of women went to the clinic to seek care for their child. Of the women who went for a visit for themselves, the most frequent motives were contraception consultation, Pap smear testing, and pre- or postnatal check-ups. The proportion of women who received the service they went to the clinic for increased between the baseline and the endline surveys from 95.8 to 97.9 percent, a statistically significant increase. The table also shows that over half the women interviewed had visited another clinic in the last three months. The proportion of women who were accompanied by their partners to one of these visits increased only slightly from 15.6 to17 percent.

In order to analyze the changes in quality of care received by women, the exit questionnaire explored in detail the care received by the women who requested contraceptive services (206 in the baseline and 216 in the endline survey). Table 9 shows that the greater proportion of these women went to the clinic for a check-up. Both in the baseline and the endline surveys, almost all women received information on all the methods available at the clinic. Although several positive changes in care were observed, only a few were statistically significant in a positive direction. The proportion of women who received the method they requested during their visit increased by nearly six percentage points (from 86.2 to $92.5 \%$ ). The proportion of women who felt the provider insisted she use a specific method decreased from 8.5 to 6.3 percent. The proportion of 
women who thought that the provider asked for permission from her partner to use the contraceptive method decreased from 38.2 to 23.8 percent.

TABLE 8: Main reasons for visiting the clinic and result of the visit Motive and result of visits

\begin{tabular}{|c|c|c|c|c|c|}
\hline \multirow[b]{3}{*}{ VARIABLES } & \multicolumn{4}{|c|}{ SURVEY } & \multirow[b]{3}{*}{ SIG* } \\
\hline & \multicolumn{2}{|c|}{$\begin{array}{c}\text { PRE } \\
(\mathrm{N}=1,060)\end{array}$} & \multicolumn{2}{|c|}{$\begin{array}{c}\text { POST } \\
(\mathrm{N}=1,062)\end{array}$} & \\
\hline & $\mathbf{N}$ & $\%$ & $\mathbf{N}$ & $\%$ & \\
\hline Contraception consultation & 206 & 19.4 & 216 & 20.3 & 0.79 \\
\hline Pre- and postnatal check-up & 160 & 15.1 & 126 & 11.8 & 0.59 \\
\hline HIVISTI & 25 & 2.4 & 45 & 4.2 & $0.00^{*}$ \\
\hline Breast exam & 22 & 2.1 & 13 & 1.2 & 0.10 \\
\hline Pap smear & 161 & 15.2 & 166 & 15.6 & 0.95 \\
\hline Child's examination & 394 & 37.2 & 392 & 36.9 & 0.60 \\
\hline Other & 167 & 15.7 & 98 & 9.2 & $0.00^{*}$ \\
\hline Received the service she was looking for & 1,015 & 95.8 & 1,040 & 97.9 & $0.01^{*}$ \\
\hline Came to the health center in the past three months & 619 & 58.4 & 583 & 54.9 & 0.19 \\
\hline $\begin{array}{l}\text { Husband came to the health center with her in the pas } \\
\text { three months }\end{array}$ & 165 & 15.6 & 181 & 17.0 & 0.05 \\
\hline
\end{tabular}

SOURCE: Exit interview, pre- and post-intervention applied by the "Effects and Costs" research

SIG*: Value of $\mathrm{P}$, which means a statistical difference between periods with a confidence level of 95 percent 
TABLE 9: Characteristics of contraceptive services

\begin{tabular}{|c|c|c|c|c|c|}
\hline \multicolumn{6}{|c|}{ Characteristics of care provided women who requested contraceptive services } \\
\hline \multirow[b]{3}{*}{ VARIABLES } & \multicolumn{4}{|c|}{ SURVEY } & \multirow[b]{3}{*}{ SIG* } \\
\hline & \multicolumn{2}{|c|}{ PRE (N=206) } & \multicolumn{2}{|c|}{$\begin{array}{c}\text { POST } \\
(\mathrm{N}=216)\end{array}$} & \\
\hline & $\mathbf{N}$ & $\%$ & $\mathbf{N}$ & $\%$ & \\
\hline \multicolumn{6}{|l|}{ Reason for contraception visit: } \\
\hline Check-up for current method & 104 & 50.5 & 136 & 62.9 & $0.03^{*}$ \\
\hline New user & 67 & 32.5 & 62 & 28.7 & \\
\hline Counseling on methods & 24 & 11.7 & 14 & 6.5 & \\
\hline Change of methods & 11 & 5.3 & 4 & 1.9 & \\
\hline $\begin{array}{l}\text { Proportion of new users seeking counseling or } \\
\text { changing method who were told of the following } \\
\text { methods: }\end{array}$ & $(102)$ & & $(80)$ & & \\
\hline -Condom & 69 & 67.6 & 62 & 77.5 & 0.07 \\
\hline -IUD & 84 & 82.3 & 72 & 90.0 & 0.06 \\
\hline -Pill & 79 & 77.4 & 64 & 80.0 & 0.48 \\
\hline -Injection & 78 & 76.5 & 65 & 81.3 & 0.29 \\
\hline -Norplant & 13 & 12.7 & 23 & 28.7 & $0.00^{*}$ \\
\hline -Female sterilization & 35 & 34.3 & 32 & 40.0 & 0.40 \\
\hline -Vasectomy & 25 & 24.5 & 26 & 32.5 & 0.18 \\
\hline -Rhythm & 65 & 63.7 & 56 & 70.0 & 0.27 \\
\hline -Withdrawal & 24 & 23.5 & 30 & 37.5 & $0.03^{*}$ \\
\hline Was given the information she wanted & 88 & 86.2 & 74 & 92.5 & $0.04^{*}$ \\
\hline Felt that a specific method was being insisted on & 9 & 8.8 & 5 & 6.3 & 0.57 \\
\hline Asked her partner permission to use the method & 39 & 38.2 & 19 & 23.8 & $0.04^{*}$ \\
\hline Who decided what method she is using: & $(104)$ & & $(136)$ & & \\
\hline She did & 31 & 29.8 & 58 & 42.6 & $0.00^{*}$ \\
\hline Partner did & 12 & 11.5 & 3 & 2.2 & \\
\hline Both & 43 & 41.3 & 53 & 38.9 & \\
\hline Provider & 2 & 1.9 & 2 & 1.5 & \\
\hline Did not answer & 16 & 15.4 & 20 & 14.7 & \\
\hline
\end{tabular}

SOURCE: Exit interview, pre- and post-intervention applied by the "Effects and Costs" research SIG*: Value of $P$, which means a statistical difference between periods with a confidence level of 95 percent

Table 10 shows variables related to client satisfaction with the services received. The percentage of women that were not satisfied with the service received decreased, although the change was not statistically significant. Nevertheless, the percentage of women who mentioned specific things they did not like, such as mistreatment, deficiencies in infrastructure, and poor organization, decreased significantly in the final evaluation. In the same way, the percentage of women who mentioned specific things they liked about the clinics increased significantly by about 10 percentage points. Notable 
among these were informational materials, infrastructure and equipment, and a more comfortable environment.

TABLE 10: Satisfaction with services

\begin{tabular}{|c|c|c|c|c|c|}
\hline \multicolumn{6}{|l|}{ Client satisfaction with the service received } \\
\hline \multirow[b]{3}{*}{ VARIABLES } & \multicolumn{4}{|c|}{ SURVEY } & \multirow[b]{3}{*}{ SIG* } \\
\hline & \multicolumn{2}{|c|}{ PRE $(\mathrm{N}=1,060)$} & \multicolumn{2}{|c|}{$\begin{array}{c}\text { POST } \\
(\mathrm{N}=1,062)\end{array}$} & \\
\hline & $\mathbf{N}$ & $\%$ & $\mathbf{N}$ & $\%$ & \\
\hline Women who were not satisfied with the service received & 74 & 7.0 & 59 & 5.5 & 0.27 \\
\hline \multicolumn{6}{|l|}{ Things clients did not like: } \\
\hline Mistreatment & 80 & 7.5 & 61 & 5.7 & 0.48 \\
\hline Too much waiting time & 132 & 12.4 & 139 & 13.1 & \\
\hline High prices & 4 & 0.3 & 10 & 0.9 & \\
\hline Poor infrastructure & 21 & 1.9 & 12 & 1.1 & \\
\hline Disorganization & 13 & 1.2 & 3 & 0.2 & \\
\hline Insufficient supply of services & 13 & 1.2 & 11 & 1.0 & \\
\hline Women who were satisfied with the services received & 749 & 70.6 & 856 & 80.6 & $0.00^{*}$ \\
\hline \multicolumn{6}{|l|}{ Things clients liked in particular: } \\
\hline Good treatment & 641 & 60.4 & 619 & 58.3 & $0.00^{*}$ \\
\hline Good organization & 43 & 4.0 & 55 & 5.2 & \\
\hline Informational materials & 10 & 0.9 & 56 & 5.3 & \\
\hline Comfortable environment & 28 & 2.6 & 46 & 4.3 & \\
\hline Affordable services & 20 & 1.8 & 16 & 1.5 & \\
\hline Infrastructure and equipment & 1 & 0.1 & 45 & 4.2 & \\
\hline
\end{tabular}

SOURCE: Exit interview, pre- and post-intervention applied by the "Effects and Costs" research

SIG*: Value of $\mathrm{P}$, which means a statistical difference between periods with a confidence level of 95 percent

\subsection{Impact of the Interventions on Unmet Need for Services and Partner Dynamics}

This study suggests that the two key variables to evaluate the effects of gender interventions in sexual and reproductive health organizations are the degree to which unmet demand for services decreases and observable changes in partner dynamics. The following two sections analyze the impact of the interventions on these two variables.

\subsubsection{Changes in unmet need for contraception}

Gender interventions in the arena of sexual and reproductive health should seek to develop women's capacity to make decisions regarding their health, increase their use of available services, and improve their sexual and reproductive lives. Women who go to clinics frequently do not know about the services that are available to them, or forget to mention a service they would like to receive. Some of these services help to give women the faculty to exert rights such as deciding the number and spacing of their children in a 
free and informed manner - a right recognized by multiple international conventions. For this reason, any gender intervention that seeks to be effective must facilitate a woman's capacity to make decisions that help her to achieve her fertility goals and rights. In other words, interventions must decrease unmet demand for sexual and reproductive health services.

There are different ways of approaching and measuring unmet needs. One way is to observe the integrality of care, that is to say, the degree to which service providers explore users' various needs and offer the services to meet them. The rate of unmet need can be defined as the proportion of women or men who would like to have received a service but left the health outlet without having received it. This definition could overlook clients to whom providers give a future appointment to provide the service. In this case, it would be better to measure clients who do not receive desired services some time after their original visit to the clinic. For this reason, this project included a followup household survey three months after the women were interviewed at the clinic.

Table 11 shows that, of the women interviewed at home three months after the clinic interview, nearly 73 percent of clients at the baseline survey and 70 percent at the endline survey had returned to the clinic after their index visit, indicating that service providers had many opportunities to satisfy their sexual and reproductive health needs.

TABLE 11: Number of visits to health outlet in a three-month period

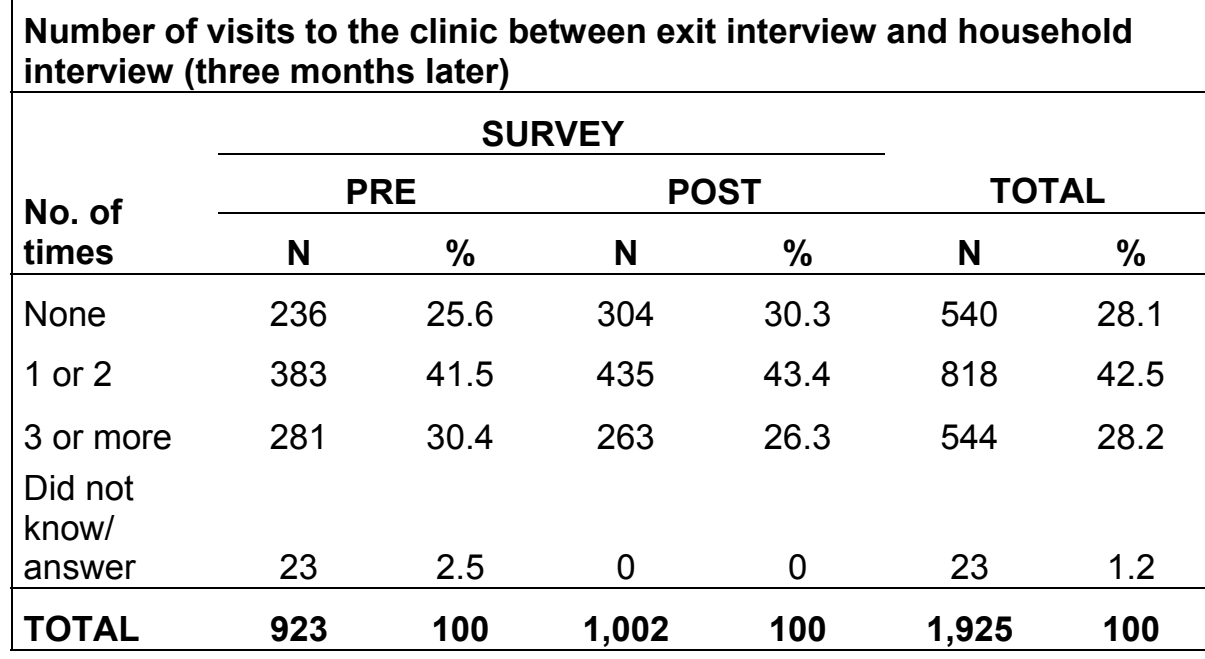

SOURCE: Household interviews / "Effects and Costs" Research 
TABLE 12: Degree to which providers screened for health service needs

\begin{tabular}{|c|c|c|c|c|c|}
\hline \multicolumn{6}{|c|}{$\begin{array}{l}\text { Women asked at least one question by the provider to explore health service } \\
\text { needs }\end{array}$} \\
\hline \multirow{3}{*}{$\begin{array}{l}\text { VARIABLE } \\
\text { Did you and the health provider } \\
\text { speak about... }\end{array}$} & \multicolumn{4}{|c|}{ SURVEY } & \multirow[b]{3}{*}{ SIG* } \\
\hline & \multicolumn{2}{|c|}{ PRE $(\mathrm{N}=1,060)$} & \multicolumn{2}{|c|}{ POST $(\mathrm{N}=1,062)$} & \\
\hline & $\mathbf{N}$ & $\%$ & $\mathbf{N}$ & $\%$ & \\
\hline \multicolumn{6}{|l|}{ Family and nutrition } \\
\hline Her family & 336 & 31.7 & 380 & 35.8 & $0.04^{*}$ \\
\hline Her nutrition & 234 & 22.1 & 291 & 27.4 & $0.00^{*}$ \\
\hline Anemia & 125 & 11.8 & 207 & 19.5 & $0.00^{*}$ \\
\hline $\begin{array}{l}\text { If she has a baby, whether she is } \\
\text { breastfeeding }\end{array}$ & 316 & 29.8 & 340 & 32.0 & 0.27 \\
\hline Mean number of affirmative answers & \multicolumn{2}{|c|}{1.66} & \multicolumn{2}{|c|}{1.95} & $0.00^{*}$ \\
\hline Standard deviation & \multicolumn{2}{|c|}{0.93} & \multicolumn{2}{|c|}{1.11} & - \\
\hline \multicolumn{6}{|l|}{ Contraception } \\
\hline $\begin{array}{l}\text { If she wishes to have (more) } \\
\text { children }\end{array}$ & 223 & 21.0 & 301 & 28.3 & $0.00^{*}$ \\
\hline $\begin{array}{l}\text { When she would like to have } \\
\text { them }\end{array}$ & 135 & 12.7 & 215 & 20.2 & $0.00^{*}$ \\
\hline Family planning use & 308 & 29.1 & 448 & 42.2 & $0.00^{*}$ \\
\hline $\begin{array}{l}\text { If she wishes to use a FP method } \\
\text { in the future }\end{array}$ & 227 & 26.1 & 395 & 37.2 & $0.00^{*}$ \\
\hline $\begin{array}{l}\text { The right to choose a } \\
\text { contraceptive method }\end{array}$ & 269 & 25.4 & 439 & 41.3 & $0.00^{*}$ \\
\hline $\begin{array}{l}\text { The right to change a } \\
\text { contraceptive method when she } \\
\text { wishes to }\end{array}$ & 230 & 21.7 & 374 & 35.2 & $0.00^{*}$ \\
\hline Mean number of affirmative answers & & & & & $0.00^{*}$ \\
\hline Standard deviation & & & & & - \\
\hline Cervical-uterine cancer & 339 & 32.0 & 458 & 43.1 & $0.00^{*}$ \\
\hline Breast cancer & 67 & 6.3 & 271 & 25.5 & $0.00^{*}$ \\
\hline AIDS & 45 & 4.2 & 172 & 16.2 & $0.00^{*}$ \\
\hline STI & 140 & 13.2 & 318 & 29.9 & $0.00^{*}$ \\
\hline Domestic and sexual violence & 47 & 4.4 & 140 & 13.2 & $0.00^{*}$ \\
\hline Sex life & 210 & 19.8 & 408 & 38.4 & $0.00^{*}$ \\
\hline
\end{tabular}

SOURCE: Exit survey / "Effects and Costs" research

SIG*: Value of $P$, which means a statistical difference between periods with a confidence level of 95 percent

Table 12 shows a significant increase in the proportion of women who reported that service providers asked them questions or gave them specific information to actively explore their health needs. About twice the number of respondents in the endline than in 
the baseline survey reported that they were asked questions or given information on cervical or breast cancer, STI/AIDS, sex life, and domestic and sexual violence. There were also significant increases in screening for family planning needs.

Beyond the exploratory questions, the surveys attempted to determine the unmet need for two services: anti-tetanus vaccine and family planning. Table 13 shows the degree to which unmet need for anti-tetanus vaccination changed among pregnant women between the baseline ( $\mathrm{N}=111$ of 923$)$ and endline $(\mathrm{N}=133$ of 1,002) surveys. Unmet need was absolute when a pregnant woman said she had never received a tetanus vaccine and was partial when a pregnant woman said she had only received one tetanus vaccine at the time of the survey. As can be seen in the table, there were no significant changes in either case.

TABLE 13: Unmet need for anti-tetanus vaccine services

\begin{tabular}{|c|c|c|c|c|c|}
\hline \multicolumn{6}{|c|}{$\begin{array}{l}\text { Pregnant women with unmet need for anti-tetanus } \\
\text { vaccine }\end{array}$} \\
\hline \multirow[b]{3}{*}{ UNMET NEED } & \multicolumn{4}{|c|}{ SURVEY } & \multirow[b]{3}{*}{ SIG* } \\
\hline & \multicolumn{2}{|c|}{ PRE (N=111) } & \multicolumn{2}{|c|}{$\begin{array}{c}\text { POST } \\
(\mathrm{N}=133)\end{array}$} & \\
\hline & $\mathbf{N}$ & $\%$ & $\mathbf{N}$ & $\%$ & \\
\hline Absolute & 11 & 9.9 & 13 & 9.8 & 0.56 \\
\hline Partial & 8 & 7.2 & 12 & 9.0 & - \\
\hline
\end{tabular}

SOURCE: Household interview, "Effects and Costs" research

SIG*: Value of $P$, which means a statistical difference between periods with a confidence level of 95 percent

Table 14 shows measurements of unmet demand for contraceptive services among married women of fertile age who are not pregnant. On all these measures there was a decrease between the baseline ( $\mathrm{N}=707$ of 923$)$ and the endline survey $(\mathrm{N}=830$ of 1,002). The first measurement corresponds to the unmet need for contraceptive methods to limit future births, that is to say, women who said they don't want to have more children and are not using a contraceptive method. The unmet need to limit births decreased from 16.4 to 14 percent in married, non-pregnant women of fertile age. At the time of the interview, these women were also asked if they would like to be using a contraceptive method. Taking the desire to use a method into account as an additional criterion, the unmet need to limit births fell between surveys from 10.6 to 7.1 percent.

The second set of measurements for unmet need focuses on the unmet need for contraception to space births. Included in this group were married, non-pregnant women of fertile age who do not wish to have a child in the next two years and are not using a contraceptive method. The unmet need for spacing dropped between surveys from 9.1 to 6.9 percent. Adding the condition that the woman would like to be using a contraceptive method, the unmet need for contraception for spacing decreased from 6.6 to 3.8 percent for the second measurement. 
TABLE 14: Unmet need for family planning services

\begin{tabular}{|lcccccc|}
\hline \multicolumn{7}{|c|}{$\begin{array}{l}\text { Married, non-pregnant women with unmet family } \\
\text { planning needs }\end{array}$} \\
\hline \multicolumn{7}{c|}{ SURVEY } \\
\hline $\begin{array}{l}\text { UNMET } \\
\text { NEED } \\
\text { FOR: }\end{array}$ & PRE (N=707) & \multicolumn{3}{c|}{$\begin{array}{c}\text { POST } \\
\text { (N=830) }\end{array}$} \\
\cline { 2 - 7 } & $\mathbf{N}$ & $\%$ & $\mathbf{N}$ & $\%$ & SIG* $^{*}$ \\
\hline $\begin{array}{l}\text { Limiting } \\
\text { Spacing }\end{array}$ & 116 & 16.4 & 116 & 14.0 & 0.18 \\
$\begin{array}{l}\text { Limiting } \\
\text { with desire } \\
\text { to use }\end{array}$ & 75 & 9.1 & 57 & 6.9 & 0.11 \\
$\begin{array}{l}\text { Spacing } \\
\text { with desire } \\
\text { to use }\end{array}$ & 43 & 10.6 & 59 & 7.1 & $0.01^{*}$ \\
\hline $\begin{array}{l}\text { Limiting } \\
\text { and } \\
\text { spacing }\end{array}$ & 180 & 25.5 & 173 & 20.8 & $0.03^{*}$ \\
\hline $\begin{array}{l}\text { Limiting } \\
\text { and } \\
\text { spacing } \\
\text { with desire } \\
\text { to use }\end{array}$ & 118 & 16.7 & 91 & 10.9 & $0.00^{*}$ \\
\hline
\end{tabular}

$\mathrm{SIG}^{*}$ : Value of $\mathrm{P}$, which means a statistical difference between periods with a confidence level of 95 percent

When combining both criteria - women who do not want to have any more children and those who do not want a child in the following two years - the change between surveys in total unmet demand for contraception dropped from 25.5 to 20.8 percent. Among women who wish to use a method, the proportion fell from 16.7 to 10.9 percent. The Gender Program interventions reduced the unmet demand for contraception by nearly 35 percent of women. In four out of six indicators a statistically significant change was observed, strengthening the conclusion that the interventions were effective in decreasing unmet need.

\subsubsection{Changes in partner dynamics}

The second crucial variable to measure the effectiveness of a gender program in organizations that offer sexual and reproductive health services is the degree to which they manage to change the dynamic of communication and decision-making among couples. To a large degree the idea of using gender as a variable of interest is based on the concept that there are inequalities within couples that affect women's health and wellbeing. Tables 15 to 21 explore the impact of the interventions on the various perceptions, attitudes, and behaviors of the women and their partners interviewed during the household follow-up survey. 
One of the greatest gender differences in Bolivia exists in access to and use of resources. Table 15 shows that a lower proportion of women in the endline survey reported that they themselves decide what to spend family income on. However, the number of women who reported that the decision was made jointly by the couple increased. Table 15 also shows that in the endline survey a greater proportion of women said they pay health, education, and food expenses with money provided by their partners and the proportion of women who spent their own money on these household expenses decreased. There was a significantly greater proportion of women who said they did not have problems asking their partners for money in the case of an important family expense. The data indicate that throughout the project, decision-making related to the use of family resources became slightly more equal.

Table 16 presents results related to communication within couples on contraception and fertility goals. In both surveys, but particularly in the endline survey, the majority of women said they could speak with ease to their husbands on subjects such as when to use family planning methods, when to have children, sexual relations, sexually transmitted diseases, and family health. A large proportion, around 80 percent, said that they had spoken with their partner on one of these subjects in the past three months. However, no significant difference was noted between the baseline and the endline surveys. Nearly 60 percent of women in both surveys believed that women should ask for permission from their partners to use a contraceptive method. Less than half the women thought that a woman had the right to use a contraceptive method without her husband's knowledge, but this proportion increased significantly after the project. There was an increase in the already high proportion of women who said they were in agreement with their partners on the use of a contraceptive method. Furthermore, the great majority of women said they were in agreement with their partners as to how many children to have, although no statistically significant changes were observed. The data suggest that the project made women feel more capable of speaking to their partners about contraceptive methods and making decisions regarding their use. 
TABLE 15: Decision-making and management of family income

\begin{tabular}{|c|c|c|c|c|c|}
\hline \multicolumn{6}{|c|}{$\begin{array}{l}\text { Married or women in union according to decision-making characteristics related to } \\
\text { management of family income }\end{array}$} \\
\hline \multirow[b]{3}{*}{ VARIABLE } & \multicolumn{4}{|c|}{ SURVEY } & \multirow[b]{3}{*}{ SIG } \\
\hline & \multicolumn{2}{|c|}{ PRE (N=792) } & \multicolumn{2}{|c|}{ POST (N=830) } & \\
\hline & $\mathbf{N}$ & $\%$ & $\mathbf{N}$ & $\%$ & \\
\hline $\begin{array}{l}\text { Who decides what money earned in the family will be } \\
\text { spent on: }\end{array}$ & & & & & $0.00^{*}$ \\
\hline Partner does & 67 & 8.5 & 71 & 8.6 & \\
\hline She does & 156 & 19.7 & 117 & 14.1 & \\
\hline Both do & 547 & 69.1 & 635 & 76.5 & \\
\hline Other & 15 & 1.9 & 7 & 0.8 & \\
\hline NA/Did not answer & 7 & 0.9 & 0 & 0.0 & \\
\hline Money with which they pay family health expenses: & & & & & $0.00^{*}$ \\
\hline Money given by the partner & 432 & 54.5 & 507 & 61.1 & \\
\hline Own money & 50 & 6.3 & 42 & 5.1 & \\
\hline Money common to both partners & 255 & 32.2 & 253 & 30.5 & \\
\hline Other & 25 & 3.2 & 5 & 0.6 & \\
\hline NA/Did not answer & 30 & 3.8 & 23 & 2.8 & \\
\hline $\begin{array}{l}\text { Money with which they pay family education } \\
\text { expenses: }\end{array}$ & & & & & $0.00^{*}$ \\
\hline Money given by partner & 306 & 38.6 & 353 & 42.5 & \\
\hline Own money & 30 & 3.8 & 21 & 2.5 & \\
\hline Money common to both partners & 188 & 23.7 & 216 & 26.0 & \\
\hline Other & 11 & 1.4 & 5 & 0.6 & \\
\hline NA/Did not answer & 257 & 32.5 & 235 & 28.3 & \\
\hline Money with which family food expenses are met: & & & & & $0.00^{*}$ \\
\hline Money given by partner & 428 & 54.0 & 494 & 59.5 & \\
\hline Own money & 54 & 6.8 & 36 & 4.3 & \\
\hline Money common to both partners & 263 & 33.2 & 277 & 33.4 & \\
\hline Other & 23 & 2.9 & 4 & 0.5 & \\
\hline NA/Did not answer & 24 & 3.0 & 19 & 2.3 & \\
\hline $\begin{array}{l}\text { When there is an important expense to be made in } \\
\text { the family and you do not have money but your } \\
\text { partner does, do you have problems asking for it? }\end{array}$ & & & & & $0.00^{*}$ \\
\hline No, never & 585 & 73.9 & 661 & 79.6 & \\
\hline Sometimes & 54 & 6.8 & 42 & 5.1 & \\
\hline Frequently & 11 & 1.4 & 5 & 0.6 & \\
\hline Yes, always & 124 & 15.7 & 122 & 14.7 & \\
\hline NA/Did not answer & 18 & 2.3 & 0 & 0.0 & \\
\hline
\end{tabular}

SOURCE: Household interview, "Effects and Costs" research

SIG*: Value of $\mathrm{P}$, which means a statistical difference between periods with a confidence level of 95 percent

Effects and Cost of Implementing a "Gender-Sensitive” Reproductive Health Program 
TABLE 16: Communication between women and their partners on family planning and fertility goals

\begin{tabular}{|c|c|c|c|c|c|}
\hline \multicolumn{6}{|c|}{ Perceptions and behaviors related to contraception and fertility goals } \\
\hline \multirow[b]{3}{*}{ VARIABLES } & \multicolumn{4}{|c|}{ SURVEY } & \multirow[b]{3}{*}{ SIG* } \\
\hline & \multicolumn{2}{|c|}{ PRE (N=931) } & \multicolumn{2}{|c|}{ POST $(\mathrm{N}=930)$} & \\
\hline & $\mathbf{N}$ & $\%$ & $\mathbf{N}$ & $\%$ & \\
\hline \multicolumn{6}{|l|}{$\begin{array}{l}\text { Do you think you can talk with your partner on the } \\
\text { following subjects: }\end{array}$} \\
\hline - When to have children & 876 & 94.1 & 881 & 94.7 & 0.68 \\
\hline - When to use family planning methods & 841 & 90.3 & 853 & 91.7 & 0.36 \\
\hline - Your sexual relations & 852 & 91.5 & 846 & 90.9 & 0.57 \\
\hline - STIs & 723 & 77.6 & 758 & 81.5 & $0.04^{*}$ \\
\hline - Family health & 906 & 97.3 & 882 & 94.8 & $0.00^{*}$ \\
\hline \multicolumn{6}{|l|}{$\begin{array}{l}\text { Have you spoken with your partner on the following } \\
\text { subjects in the last three months: }\end{array}$} \\
\hline - When to have children & 791 & 84.9 & 767 & 82.5 & 0.11 \\
\hline - When to use FP methods & 751 & 80.6 & 728 & 78.3 & 0.18 \\
\hline - Your sexual relations & 796 & 85.5 & 735 & 79.0 & $0.04^{*}$ \\
\hline - STIs & 599 & 64.3 & 589 & 63.3 & 0.63 \\
\hline - Family health & 880 & 94.5 & 826 & 88.8 & $0.00^{*}$ \\
\hline $\begin{array}{l}\text { Do you think women should ask their partner for } \\
\text { permission to use a method? }\end{array}$ & 577 & 61.9 & 557 & 59.9 & 0.54 \\
\hline $\begin{array}{l}\text { Do you think women have the right to use a method } \\
\text { without her partner's knowledge? }\end{array}$ & 379 & 40.7 & 464 & 49.9 & $0.00^{*}$ \\
\hline $\begin{array}{l}\text { Are you in agreement with your partner in using a } \\
\text { method? }\end{array}$ & 795 & 85.4 & 796 & 85.6 & 0.99 \\
\hline $\begin{array}{l}\text { Are you in agreement with your partner as to how many } \\
\text { children to have? }\end{array}$ & 833 & 89.4 & 832 & 89.5 & 0.88 \\
\hline
\end{tabular}

SOURCE: Exit interview, pre- and post-intervention applied by the "Effects and Costs" research

SIG*: Value of P, which means a statistical difference between periods with a confidence level of 95 percent

Tables 17-20 compare baseline and endline survey results, as well as women and their partners' answers with regards to various aspects of partner dynamics. Table 17 explores the couples' perceptions of the degree to which the man attempts to control the woman. Among the women there were practically no significant changes between surveys in the individual items, but for the sum of all questions there was a significant change in the desired direction. In contrast, the proportion of men that said they always decided what their partner had to do, forbade her from wearing certain kinds of clothes, and did not allow her to speak in social gatherings diminished significantly between the surveys.

Table 17 shows that less than a third of men and women say that the man tries to control his partner in matters such as what the woman has to do, how she should dress, or forbidding her to speak to or go out with certain people. There are also few (around 25\%) men and women that say that the man almost always gets his way when they argue, or that the man does what he wants whether she likes it or not. Over 80 percent of both men 
and women say that the man always wants to know where his partner is. Perhaps optimistically, almost twice the number of men than women say the man is the one who generally makes the decisions necessary to solve problems that affect the family. Women interviewed agreed that there are an average of 3.6 male dominant behaviors per couple in the pretest compared to 3.3 in the post-test, a statistically significant decrease. Males' evaluations of their dominant behaviors decreased from 3.2 to 2.8 per couple. 
TABLE 17: Perception of the control men have over women

\begin{tabular}{|c|c|c|c|c|c|}
\hline \multicolumn{6}{|l|}{ Perceptions of partner's control over decisions } \\
\hline \multirow[b]{3}{*}{ VARIABLES } & \multicolumn{4}{|c|}{ SURVEY } & \multirow[b]{3}{*}{ SIG* } \\
\hline & \multicolumn{2}{|c|}{ PRE (N=792) } & \multicolumn{2}{|c|}{$\begin{array}{c}\text { POST } \\
(\mathrm{N}=830)\end{array}$} & \\
\hline & $\mathbf{N}$ & $\%$ & $\mathbf{N}$ & $\%$ & \\
\hline \multicolumn{6}{|l|}{ WOMEN } \\
\hline \multicolumn{6}{|l|}{ On most occasions, your partner: } \\
\hline Decides what you have to do & 276 & 34.8 & 255 & 30.7 & 0.28 \\
\hline Does not allow you to wear certain clothes & 197 & 24.5 & 182 & 21.9 & 0.38 \\
\hline Provides solutions to problems that affect both of you & 359 & 45.3 & 324 & 39.0 & 0.09 \\
\hline Forbids you to speak to or go out with certain people & 252 & 31.8 & 242 & 29.1 & 0.59 \\
\hline Always wants to know where you are & 657 & 82.9 & 684 & 82.4 & 0.24 \\
\hline Always does what he likes whether you want to or not & 306 & 38.6 & 316 & 38.0 & 0.65 \\
\hline $\begin{array}{l}\text { When you argue with your partner, he almost always gets } \\
\text { what he wants }\end{array}$ & 274 & 34.5 & 291 & 35.0 & 0.41 \\
\hline In general you are quiet when you are with your partner & 214 & 27.0 & 211 & 25.4 & 0.85 \\
\hline You are unhappy with your relationship with your partner & 153 & 19.3 & 151 & 18.1 & 0.88 \\
\hline \multicolumn{6}{|l|}{ Average number of affirmative answers } \\
\hline Mean & \multicolumn{2}{|c|}{3.60} & \multicolumn{2}{|c|}{3.37} & $0.03^{*}$ \\
\hline Standard deviation & \multicolumn{2}{|c|}{2.16} & \multicolumn{2}{|l|}{2.03} & - \\
\hline MEN & $(212)$ & & $(318)$ & & \\
\hline \multicolumn{6}{|l|}{ On most occasions: } \\
\hline You decide what your partner should do & 88 & 41.5 & 96 & 30.1 & $0.01^{*}$ \\
\hline You do not allow her to wear certain clothes & 57 & 26.9 & 53 & 16.6 & $0.00^{*}$ \\
\hline You make the decision on problems that affect both of you & 132 & 62.2 & 172 & 54.0 & $0.05^{*}$ \\
\hline You forbid her to speak to or go out with certain people & 64 & 30.2 & 93 & 29.2 & 0.77 \\
\hline You almost always want to know where she is & 189 & 89.2 & 284 & 89.3 & 0.96 \\
\hline You always do what you want whether she likes to or not & 52 & 24.5 & 74 & 23.2 & 0.72 \\
\hline $\begin{array}{l}\text { When you argue with your partner, you almost always get } \\
\text { what you want }\end{array}$ & 50 & 23.6 & 81 & 25.4 & 0.63 \\
\hline $\begin{array}{l}\text { You do not allow your partner to speak much when she is } \\
\text { in social gatherings }\end{array}$ & 52 & 24.5 & 45 & 14.1 & $0.00^{*}$ \\
\hline \multicolumn{6}{|l|}{ Average number of affirmative answers } \\
\hline Mean & \multicolumn{2}{|c|}{3.23} & \multicolumn{2}{|c|}{2.82} & $0.01^{*}$ \\
\hline Standard deviation & \multicolumn{2}{|c|}{1.87} & \multicolumn{2}{|l|}{1.73} & - \\
\hline
\end{tabular}

SOURCE: Household interview applied by the "Effects and Costs" research

SIG*: Value of $\mathrm{P}$, which means a statistical difference between periods with a confidence level of 95 percent 
Table 18 illustrates the degree to which the women and men interviewed supported certain affirmations based on gender stereotypes. In the case of women, statistically significant changes were observed for three of the five indicators, while in the case of men, there was only one significant change. Over half the women believed that men need to have more sex than women, and that it is not correct for women to initiate sexual relations. Surprisingly, twice the number of women compared to men say it is not good for women to have sexual relations before marriage. Table 18 does not show that the project had an effect on gender stereotypes. Although there were many significant changes they were frequently in a direction opposite to the one expected.

\section{TABLE 18: Perceptions of gender roles}

\begin{tabular}{|c|c|c|c|c|c|}
\hline \multicolumn{6}{|l|}{ Affirmative answers on variables related to gender roles } \\
\hline \multirow[b]{3}{*}{ VARIABLES } & \multicolumn{4}{|c|}{ SURVEY } & \multirow[b]{3}{*}{ SIG* } \\
\hline & \multicolumn{2}{|c|}{$\begin{array}{c}\text { PRE } \\
(\mathrm{N}=923)\end{array}$} & \multicolumn{2}{|c|}{$\begin{array}{c}\text { POST } \\
(\mathrm{N}=1,002)\end{array}$} & \\
\hline & $\mathbf{N}$ & $\%$ & $\mathbf{N}$ & $\%$ & \\
\hline \multicolumn{6}{|l|}{ WOMEN } \\
\hline \multicolumn{6}{|l|}{ Women who agreed with the following affirmations: } \\
\hline Men need to have more sex than women do & 491 & 53.2 & 588 & 58.7 & $0.01^{*}$ \\
\hline It is not correct for a women to initiate sexual relations & 520 & 56.3 & 521 & 52.0 & $0.05^{*}$ \\
\hline Woman's work should mainly be at home (cleaning, cooking) & 425 & 46.0 & 276 & 27.5 & $0.00^{*}$ \\
\hline It is good for a man to have sexual relations before marriage & 339 & 36.7 & 349 & 34.8 & 0.38 \\
\hline $\begin{array}{l}\text { It is not good for a woman to have sexual relations before } \\
\text { marriage }\end{array}$ & 682 & 73.9 & 752 & 75.0 & 0.55 \\
\hline \multicolumn{6}{|l|}{ Average number of affirmative answers } \\
\hline Mean & \multicolumn{2}{|c|}{2.32} & 2.34 & & \multirow[t]{2}{*}{0.67} \\
\hline Standard deviation & \multicolumn{2}{|c|}{1.38} & 1.14 & & \\
\hline MEN & $(212)$ & & $(318)$ & & \\
\hline \multicolumn{6}{|l|}{ Men who agreed with the following affirmations: } \\
\hline Men need to have more sex than women do & 106 & 50.0 & 184 & 57.8 & 0.12 \\
\hline It is not correct for a women to initiate sexual relations & 125 & 58.9 & 205 & 64.5 & 0.24 \\
\hline Woman's work should mainly be at home (cleaning, cooking) & 90 & 42.5 & 90 & 28.3 & $0.00^{*}$ \\
\hline It is good for a man to have sexual relations before marriage & 125 & 59.0 & 199 & 62.6 & 0.63 \\
\hline $\begin{array}{l}\text { It is not good for a woman to have sexual relations before } \\
\text { marriage }\end{array}$ & 78 & 37.3 & 132 & 41.5 & 0.25 \\
\hline \multicolumn{6}{|l|}{ Average number of affirmative answers } \\
\hline Mean & \multicolumn{2}{|c|}{2.5} & \multicolumn{2}{|l|}{2.3} & 0.17 \\
\hline Standard deviation & \multicolumn{2}{|c|}{1.23} & 1.02 & & - \\
\hline
\end{tabular}

SOURCE: Household interview applied by the "Effects and Costs" research

SIG*: Value of $P$, which means a statistical difference between periods with a confidence level of 95 percent

Table 19 explores beliefs as to when a woman can refuse to have sexual relations with her partner. Almost all women and men interviewed said that the woman could turn down 
sexual relations whenever she wanted to and under conditions such as when she had just given birth or when she knew her partner had a sexually transmitted infection. Despite the high baseline levels, the proportion of women that agreed with these statements increased significantly throughout the project. The proportion of married or women in union who believe that their partners care whether they enjoy their sex lives also increased, as did the number who felt confident enough to ask their partners for special caresses or to avoid things they did not like. The number who believed their partners would pay attention if they asked for these things also improved. Positive changes were also found for men, but in seven of nine cases the differences found were not statistically significant.

Table 20 explores beliefs and behaviors related to intimate partner violence against woman. The proportion of women who believed that there are circumstances in which men have the right to beat their partners decreased significantly from 4.4 to 1.8 percent. No significant changes were found among men, but it is surprising that almost 15 percent of them considered it their right to beat women in some cases, especially when a woman has sexual relations with another man, when the woman does not take proper care of her children, or when she refuses to prepare food. Table 20 shows the reported levels of violence against women by their intimate companions did not change during the project. Nearly one-third of women in both surveys said they had had serious fights with their partners in the past year. Nearly 15 percent reported having been beaten by their partners in the past year, and nearly 10 percent reported having been forced to have sexual relations against her will in the past year. 
TABLE 19: Perceptions of rights and partner communication on sexuality

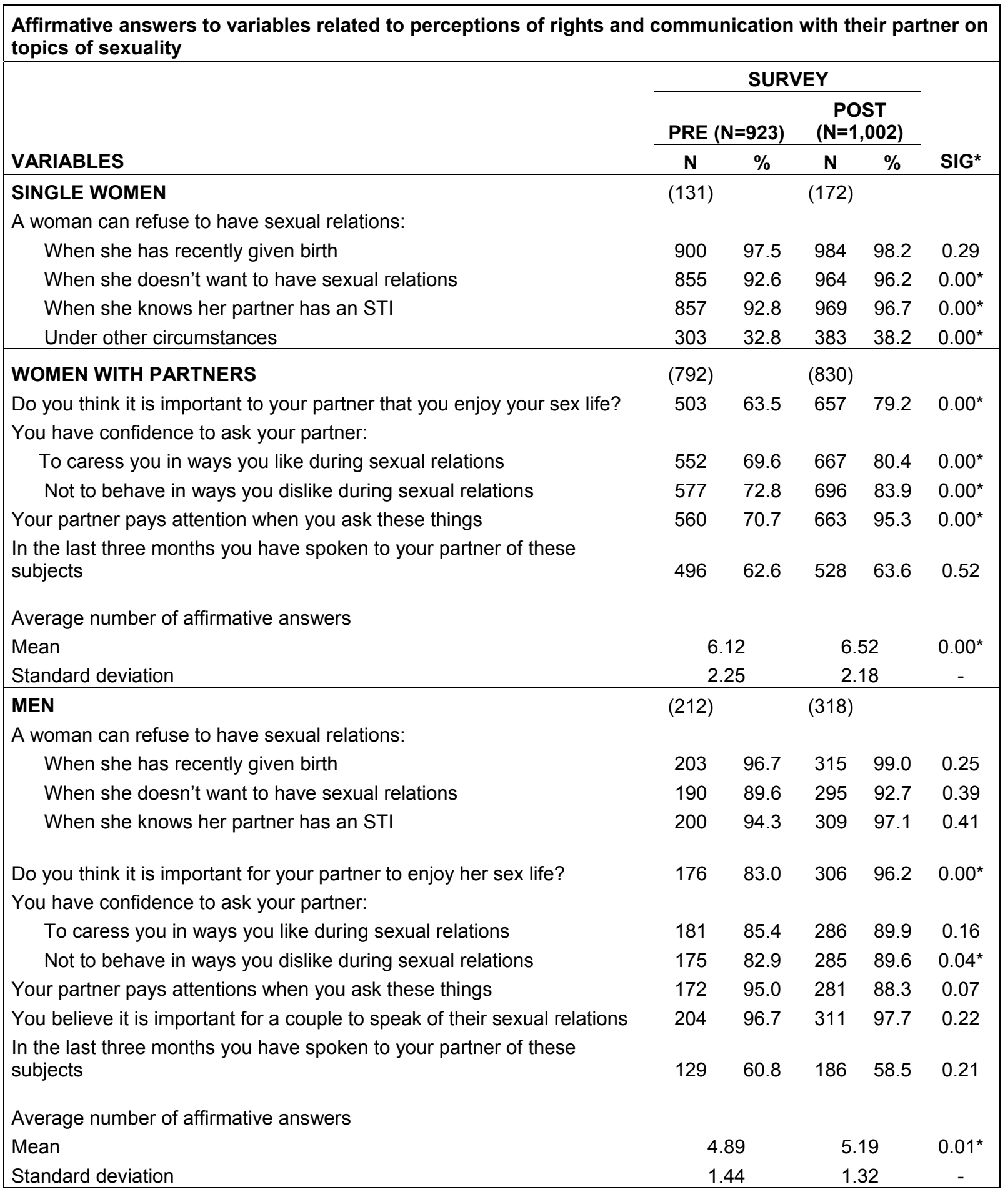

SOURCE: Household survey, "Effects and Costs" research

SIG*: Value of $P$, which means a statistical difference between periods with a confidence level of 95 percent 
TABLE 20: Perception of gender-based violence

\begin{tabular}{|c|c|c|c|c|c|}
\hline \multicolumn{5}{|l|}{ Affirmative responses to questions related to domestic violence } & \multirow[b]{4}{*}{ SIG* } \\
\hline \multirow[b]{3}{*}{ VARIABLES } & \multicolumn{4}{|c|}{ SURVEY } & \\
\hline & \multicolumn{2}{|c|}{$\begin{array}{c}\mathrm{PRE} \\
(\mathrm{N}=923)\end{array}$} & \multicolumn{2}{|c|}{$\begin{array}{c}\text { POST } \\
(\mathrm{N}=1,002)\end{array}$} & \\
\hline & $\mathbf{N}$ & $\%$ & $\mathbf{N}$ & $\%$ & \\
\hline \multirow{2}{*}{$\begin{array}{l}\text { SINGLE WOMEN } \\
\text { A man has the right }\end{array}$} & (131) & & (172) & & \\
\hline & 41 & 4.4 & 18 & 1.8 & $0.00^{*}$ \\
\hline \multirow{2}{*}{$\begin{array}{l}\text { WOMEN WITH PARTNERS } \\
\text { Have you had serious arguments with your partner in the last } \\
\text { year? }\end{array}$} & (792) & & (830) & & \\
\hline & 268 & 33.8 & 285 & 34.3 & 0.41 \\
\hline Have you been beaten by your partner in the last year? & 113 & 14.2 & 97 & 11.6 & 0.23 \\
\hline Have you been forced to have sexual relations in the last year? & 84 & 10.6 & 78 & 9.3 & 0.61 \\
\hline \multicolumn{6}{|l|}{ Average number of affirmative answers } \\
\hline Mean & \multicolumn{2}{|c|}{1.50} & \multicolumn{2}{|c|}{1.44} & 0.24 \\
\hline Standard deviation & \multicolumn{2}{|c|}{0.72} & \multicolumn{2}{|c|}{0.67} & - \\
\hline MEN & (212) & & (318) & & \\
\hline A man has the right to beat his partner & 36 & 17.0 & 45 & 14.1 & 0.49 \\
\hline Reasons why he has a right to: & (36) & & (45) & & \\
\hline When she neglects the children & 21 & 58.3 & 30 & 66.7 & 0.43 \\
\hline When she argues back & 11 & 30.6 & 15 & 33.3 & 0.07 \\
\hline If she refuses to have sex when he wants to & 0 & 0.0 & 3 & 6.7 & NA \\
\hline If she talks of sexual health or contraception & 1 & 2.8 & 3 & 6.7 & NA \\
\hline If she refuses to prepare food & 15 & 41.7 & 22 & 48.9 & 0.11 \\
\hline If she has had sexual relations with another man & 30 & 83.3 & 42 & 93.3 & 0.13 \\
\hline Other reasons & 7 & 19.4 & 8 & 17.8 & 0.07 \\
\hline
\end{tabular}

SOURCE: Household survey, "Effects and Costs" research

SIG*: Value of $\mathrm{P}$, which means a statistical difference between periods with a confidence level of 95 percent

\subsection{Changes in Demand for Services}

To analyze the impact of the intervention on the demand for sexual and reproductive health services, we compared the periods between January 2001 and March 2002 (prior to the Gender Program intervention) with the period from April 2002 to June 2003 (when the intervention was implemented). The most important services offered by these institutions are compared: prenatal, delivery, and postnatal check-ups; contraception; STI testing; PAP smears; and counseling. We also compared NGO services with public services that are managed by the state but receive technical assistance from PROCOSI's NGO network.

Table 21 shows that significant changes can be observed between the baseline and endline only in the case of some contraceptive services. Mean monthly visits per clinic 
decreased from three to two visits for new pill users and from six to three visits for new condom users. The mean number of visits by continuing users of natural methods also decreased significantly from eight to three per month. On the other hand, the mean number of visits for new and continuing users of injectables increased significantly from seven to nine and from 22 to 30, respectively.

When the results are compared according to the type of clinic management, there was a significant increase in public clinics in mean number of monthly visits by prenatal care clients from 76 to 101 and a nearly significant increase in counseling services from 95 to 126. For contraception visits, significant increases occurred in the state clinics in the number of visits by new condom users and by new and continuing injection users. The other significant change was a strong decrease in visits by continuing users of natural methods from 18 to four visits. In the case of clinics managed directly by NGOs, significant decreases were only observed in the monthly average of visits by new pill users and continuing condom users.

As presented in the following graphs, it is difficult to attribute the few significant increases observed between the study periods to the intervention. Graph 2, for example, presents the monthly averages of new and continuing users of injections in public clinics. There is an increasing trend that began during the period preceding the project that did not undergo great changes once the project activities began. The same phenomenon can be observed in Graph 3, which presents the mean monthly number of prenatal visits. In conclusion, the project seems to have had few effects on the demand for reproductive health services in participating clinics. 
TABLE 21: Comparison of private and public clinics' services

\begin{tabular}{|c|c|c|c|c|c|c|c|c|c|}
\hline \multicolumn{10}{|c|}{ Mean monthly number of visits by type of service and type of clinic management } \\
\hline \multirow[b]{2}{*}{ SERVICE } & \multicolumn{3}{|c|}{ PRIVATE } & \multicolumn{3}{|c|}{ PUBLIC } & \multicolumn{3}{|c|}{ TOTAL } \\
\hline & $\begin{array}{c}\text { Mean } \\
\text { Period } 1\end{array}$ & $\begin{array}{c}\text { Mean } \\
\text { Period } 2\end{array}$ & SIG* $^{*}$ & $\begin{array}{c}\text { Mean } \\
\text { Period } 1\end{array}$ & $\begin{array}{c}\text { Mean } \\
\text { Period } 2 \\
\end{array}$ & $\mathbf{S I G}^{*}$ & $\begin{array}{c}\text { Mean } \\
\text { Period } 1\end{array}$ & $\begin{array}{c}\text { Mean } \\
\text { Period } 2\end{array}$ & SIG* \\
\hline \multicolumn{10}{|l|}{ Prenatal: } \\
\hline New & 36 & 35 & 0.69 & 44 & 48 & 0.27 & 39 & 39 & 0.97 \\
\hline Repeat & 46 & 42 & 0.34 & 76 & 101 & $0.02^{*}$ & 55 & 60 & 0.41 \\
\hline Natal & 8 & 7 & 0.34 & 27 & 28 & 0.75 & 14 & 13 & 0.71 \\
\hline Postnatal & 6 & 6 & 0.83 & 24 & 20 & 0.10 & 12 & 10 & 0.34 \\
\hline STI & 2 & 2 & 0.89 & 1 & 1 & 0.70 & 2 & 2 & 0.81 \\
\hline Pap smear & 62 & 76 & 0.91 & 24 & 18 & 0.06 & 51 & 58 & 0.35 \\
\hline Counseling & 89 & 82 & 0.65 & 95 & 126 & $0.05^{*}$ & 91 & 96 & 0.67 \\
\hline Total & 249 & 250 & 0.73 & 291 & 342 & 0.26 & 264 & 278 & 0.45 \\
\hline \multicolumn{10}{|l|}{ CONTRACEPTION } \\
\hline \multicolumn{10}{|l|}{ Pill : } \\
\hline New & 3 & 2 & $0.05^{*}$ & 2 & 2 & 0.35 & 3 & 2 & $0.03^{*}$ \\
\hline Continuing & 17 & 20 & 0.54 & 2 & 2 & 0.71 & 12 & 15 & 0.54 \\
\hline \multicolumn{10}{|l|}{ IUD: } \\
\hline New & 9 & 9 & 0.96 & 9 & 8 & 0.38 & 9 & 8 & 0.73 \\
\hline Continuing & 26 & 24 & 0.63 & 19 & 19 & 0.84 & 24 & 23 & 0.61 \\
\hline \multicolumn{10}{|l|}{ Condom: } \\
\hline New & 4 & 3 & 0.13 & 2 & 3 & $0.00^{*}$ & 3 & 3 & 0.49 \\
\hline Continuing & 8 & 4 & $0.03^{*}$ & 1 & 1 & 0.22 & 6 & 3 & $0.04^{*}$ \\
\hline \multicolumn{10}{|l|}{ Injection: } \\
\hline New & 7 & 8 & 0.61 & 7 & 13 & $0.00^{*}$ & 7 & 9 & $0.03^{*}$ \\
\hline Continuing & 24 & 31 & 0.18 & 17 & 28 & $0.00^{*}$ & 22 & 30 & $0.02^{*}$ \\
\hline \multicolumn{10}{|l|}{ Natural methods: } \\
\hline New & 3 & 4 & 0.35 & 27 & 17 & 0.16 & 10 & 8 & 0.36 \\
\hline Continuing & 4 & 3 & 0.49 & 18 & 4 & 0.02 & 8 & 3 & $0.02^{*}$ \\
\hline Female sterilization & 0 & 0 & 0.75 & 0 & 0 & 0.76 & 0 & 0 & 0.85 \\
\hline Vasectomy & 0 & 0 & 0.41 & 0 & 0 & - & 0 & 0 & 0.15 \\
\hline Total & 105 & 108 & 0.75 & 104 & 97 & 0.65 & 104 & 104 & 0.98 \\
\hline Grand Total & 354 & 358 & 0.96 & 395 & 439 & 0.24 & 368 & 382 & 0.60 \\
\hline
\end{tabular}

SOURCE: Data obtained from the National System of Health Information and verified on the field, before being entered in Form 07 of the "Effects and Costs" research

$S G^{*}$ : Value of $P$, which means a statistical difference between periods with a confidence level of 95 percent 

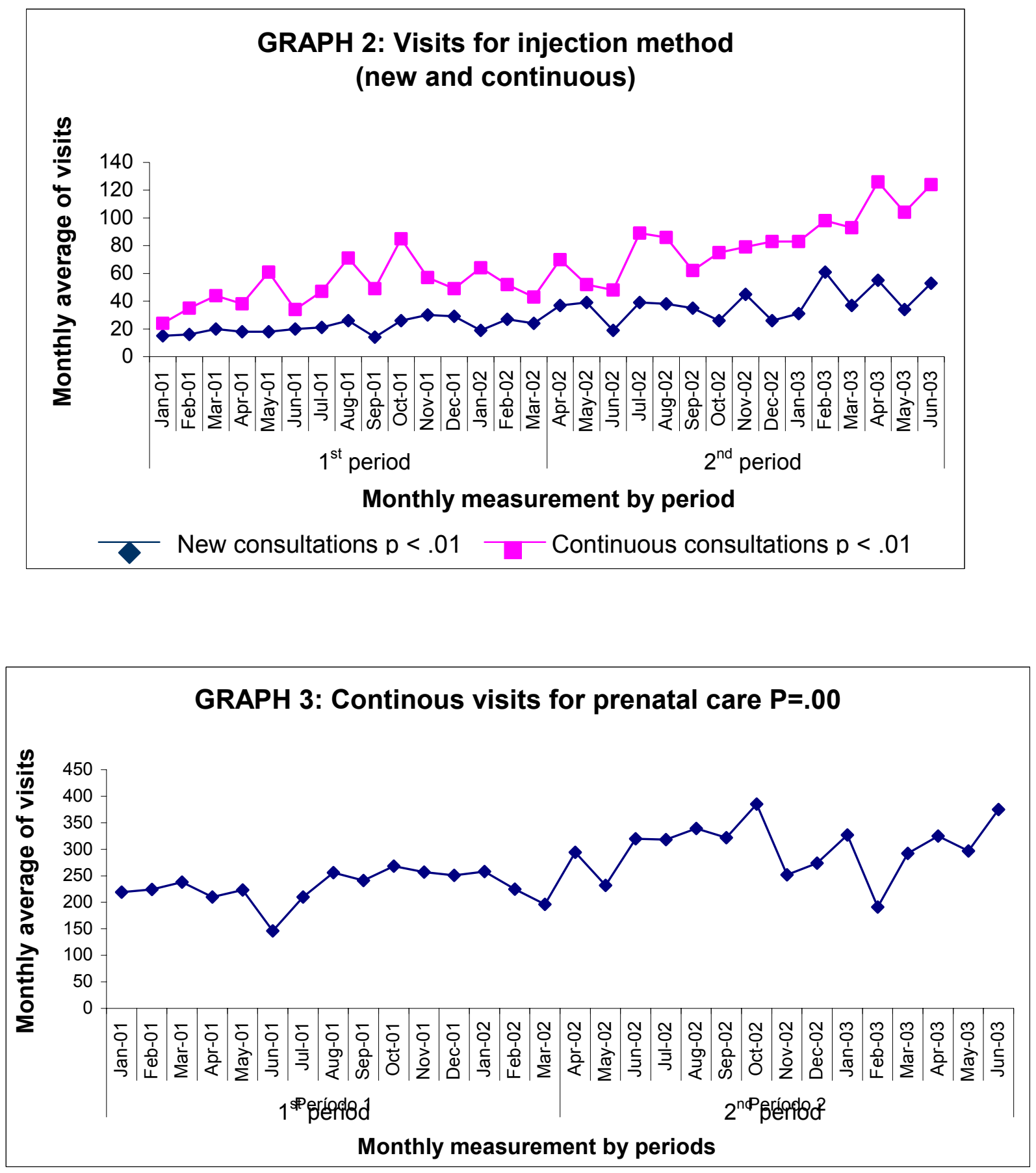


\subsection{Cost of Introducing a Gender Perspective}

The costs of interventions to adopt a gender perspective are important to consider when deciding whether such interventions should be replicated. This section provides information on the costs of the entire process that culminated in implementation of specific interventions by the participating agencies. The focus of the cost analysis includes both financial costs (actual outlays of funds to purchase resources) and nonfinancial costs (costs of resources that were used in the interventions but which PROCOSI did not purchase). This broad perspective considers the costs of all resources used in the project implementation, regardless of who paid for them. ${ }^{13}$

The economic analysis considered costs associated with the two main stages in designing and implementing the interventions to introduce a gender perspective:

- An initial assessment conducted by the NGOs to measure baseline indicators of the situation and decide which interventions were needed.

- The design and the implementation of the interventions to improve the quality of care from a gender perspective.

The objectives of this component were therefore defined in the following way:

- To measure the costs of the baseline assessment and the development of the action plan designed to improve the quality of care, as well as the cost of its implementation (i.e., the interventions).

- To measure any change in the costs of service provision that occur as a result of the implementation of the interventions.

The costs of the final evaluation conducted in each NGO are not included in the economic component because this activity would not be part of a replication of the Gender Project. Results are presented in U.S. dollars using an average exchange rate of $\$ \mathrm{US} 1=7.11$ Bolivianos. This rate reflects the midpoint of exchange rates when the interventions began (US $\$ 1=6.45 \mathrm{Bs}$.) and when they ended (US $\$ 1=7.76 \mathrm{Bs}$.).

Table 22 presents a summary of the total costs incurred by each NGO in activities of the gender project as defined above. Costs include those incurred locally within the NGOs during the planning phase and in implementing the interventions. Most of the costs were non-financial and included PROCOSI staff time to train, supervise, and develop and distribute IEC materials. Because the costs incurred by PROCOSI corresponded to activities carried out to benefit all of the participating NGOs, these were distributed evenly across all NGOs.

13 This perspective reflects the economic concept of "opportunity cost," which is the value of the resource in its most productive alternative use.

Effects and Cost of Implementing a "Gender-Sensitive" Reproductive Health Program 
TABLE 22: Total cost of implementation of the gender project, by NGO

\begin{tabular}{|c|c|c|c|}
\hline \multicolumn{4}{|c|}{ Total costs of activities related to the gender project by NGO } \\
\hline \multirow[b]{2}{*}{ NGO } & \multicolumn{3}{|c|}{ Cost (US\$) } \\
\hline & NGO costs & $\begin{array}{c}\text { PROCOSI } \\
\text { costs }^{* *}\end{array}$ & TOTAL COSTS \\
\hline 1 & 9,895 & 8,002 & 17,897 \\
\hline 2 & 14,215 & 8,002 & 22,217 \\
\hline 3 & 12,951 & 8,002 & 20,953 \\
\hline 4 and $6^{*}$ & 28,315 & 8,002 & 36,317 \\
\hline 5 & 9,085 & 8,002 & 17,087 \\
\hline 7 & 9,538 & 8,002 & 17,540 \\
\hline 8 & 11,964 & 8,002 & 19,966 \\
\hline 9 & 21,280 & 8,002 & 29,282 \\
\hline 10 & 19,072 & 8,002 & 27,074 \\
\hline TOTAL & & & $\$ 208,333$ \\
\hline AVERAG & NGO & & $\$ 23,148$ \\
\hline
\end{tabular}

* This NGO has two clinics that participated and their costs are combined

${ }^{* *}$ Total costs incurred by PROCOSI were allocated equally to the 17 institutions that participated in the gender project

Table 22 shows that the average cost of the gender interventions among the nine NGOs studied was US\$23,148. Total costs varied substantially across the nine NGOs, reflecting the different mix and intensity of interventions that were implemented.

Table 23 presents more information on the individual elements that made up the overall cost of the time invested by PROCOSI in the gender project. These costs include time spent on design, production and distribution of IEC materials, design and implementation of a broad range of skill-building workshops, and overall supervision and support of project activities.

TABLE 23: Contributions from the executive secretariat of PROCOSI

\begin{tabular}{|lc|}
\hline \multicolumn{2}{|l|}{$\begin{array}{l}\text { Distribution of the costs of PROCOSI technical and administrative } \\
\text { assistance }\end{array}$} \\
\hline Item & Cost (US\$) \\
\hline Staff investment in time* & 20,746 \\
Investment in workshops and training & 82,739 \\
Creation and distribution of IEC materials & 32,451 \\
Grand Total & $\mathbf{\$ 1 3 6 , 0 2 6}$ \\
\hline
\end{tabular}

*Technical support: RHS and IEC, organization of workshops and training sessions, bibliography compilation, management of funds, accounting, and others. 
Table 24 presents the costs incurred locally by each NGO. The highest-cost activity corresponds to the time invested by NGO staff (including technical personnel, coordinators, service providers, and clinic directors) in conducting the baseline assessment and implementing the interventions. These are considered non-financial costs because the participating institutions covered the salaries of participating staff. PROCOSI gave each NGO a grant of $\$ 3,500$ to help cover the costs of the interventions, and these funds were used mainly to purchase equipment, make improvements to infrastructure, and to pay for staff attendance at workshops. The second-highest cost is associated with workshops or training including lodging, travel, and meal expenses. Lesser expenses correspond to capital costs associated with purchases of equipment and improvements to clinic infrastructure; most of these were financial costs financed with the grant PROCOSI provided to each NGO.

TABLE 24: Total NGO costs of gender projects (US\$)

\begin{tabular}{|lccccccc|}
\hline NGO & Staff time & $\begin{array}{c}\text { Workshops } \\
\text { and } \\
\text { training** }\end{array}$ & $\begin{array}{c}\text { Policy } \\
\text { Infrastruct- } \\
\text { ure and } \\
\text { equipment }\end{array}$ & $\begin{array}{c}\text { changes } \\
\text { and } \\
\text { institutional } \\
\text { guidelines }\end{array}$ & Supervision & $\begin{array}{c}\text { IEC } \\
\text { materials }\end{array}$ & TOTAL \\
\hline 1 & 3,906 & 3,275 & 51 & 2,438 & 225 & 0 & $\mathbf{9 , 8 9 5}$ \\
2 & 5,709 & 1,369 & 154 & 1,049 & 5,726 & 208 & $\mathbf{1 4 , 2 1 5}$ \\
3 & 10,704 & 649 & 168 & 1,430 & 0 & 0 & $\mathbf{1 2 , 9 5 1}$ \\
4 and $6^{*}$ & 23,352 & 858 & 35 & 0 & 583 & 3,487 & $\mathbf{2 8 , 3 1 5}$ \\
5 & 6,330 & 1,226 & 138 & 637 & 754 & 0 & $\mathbf{9 , 0 8 5}$ \\
7 & 6,511 & 2,001 & 0 & 0 & 0 & 1,026 & $\mathbf{9 , 5 3 8}$ \\
8 & 7,586 & 849 & 504 & 2,952 & 73 & 0 & $\mathbf{1 1 , 9 6 4}$ \\
9 & 11,222 & 6,119 & 189 & 1,475 & 1,533 & 742 & $\mathbf{2 1 , 2 8 0}$ \\
10 & 17,760 & 564 & 381 & 233 & 134 & 0 & $\mathbf{1 9 , 0 7 2}$ \\
\hline Total & $\mathbf{9 3 , 0 8 0}$ & $\mathbf{1 6 , 9 1 0}$ & $\mathbf{1 6 2 0}$ & $\mathbf{1 0 , 2 1 4}$ & $\mathbf{9 , 0 2 8}$ & $\mathbf{5 , 4 6 3}$ & $\mathbf{\$ 1 3 6 , 3 1 5}$ \\
\hline
\end{tabular}

* This NGO has two clinics that participated and their costs are combined

** Office supplies, photocopies, mail, telephone, rent of facilities and equipment, coffee breaks, transportation for meetings, and other miscellaneous expenditures 


\section{CONCLUSIONS AND RECOMMENDATIONS}

This research proposed to answer four questions. This section summarizes the results and answers the questions posed.

1) Can health organizations incorporate a gender perspective and improve quality of service?

Results show that sexual and reproductive health service organizations can implement action plans to change organizational policies and service delivery practices and to improve their infrastructure and equipment to make them more convenient for clients. The changes observed in this research were relatively modest, but represent movement in the right direction. Noticeable changes in provider practices included more respectful treatment of clients, greater screening for their service needs, attempts to involve men, and greater use of didactic material while counseling clients. A greater proportion of clients received the service they went to the clinic for. As a consequence, user satisfaction with the services has increased. A second noteworthy change was in the personal vision of health service providers, who seem to have appropriated gender as a consideration to analyze and use in their personal lives.

The methodology used by PROCOSI to introduce a gender perspective to their affiliates consisted of creating work plans to modify some of the indicators on the list prepared by IPPF that were found to be insufficient during the pretest. In theory, organizations that adopt a gender perspective should comply with the majority of indicators included on the IPPF list. For this reason, PROCOSI recommends that in future research a methodology similar to the one used in the Baby-Friendly Hospitals experiment be used. In this project, hospitals had to achieve favorable scores on a minimum of 80 percent of the indicators in order to be certified as "baby friendly" and were subject to external evaluation. This methodology would help to ensure that participating organizations truly adopt a gender perspective and improve their quality of care.

2) If sexual and reproductive health service providers manage to incorporate gender and quality perspectives, does this have a positive effect on the health and well being of clients and, more specifically, on their unmet need for services? Do partner relationships change as a result of the improved services?

To evaluate the impact of the intervention on clients, researchers evaluated two variables: the unmet need for reproductive and sexual health services and changes in partner dynamics.

Exit interviews with users established that service providers effectively made an important effort to check their clients' needs more systematically in less than half the cases attended. To measure the impact of the systematic screening efforts, researchers calculated the unmet need for toxoid anti-tetanus vaccinations among pregnant women and no change was found. However, the unmet need for contraceptive services showed statistically significant decreases after the interventions. The decrease in the total unmet 
need for contraceptive services between the baseline and endline surveys was nearly 35 percent (from 16.7 to $10.9 \%$ of married women of fertile age), a considerable decrease.

With regard to this finding there are three important considerations. The first is a recommendation to explore strategies and systems that allow health service providers to evaluate their clients' needs in a more systematic fashion. If the 35 percent decrease in unmet need can be reached by checking the needs of less than half the users, it is logical to expect a greater reduction if the strategy were applied universally. The second consideration is related to the definition of unmet need using the desire to use a method and not only the disparity between reproductive goals and exposure to pregnancy. It is evident that the first definition leads to a much more precise measurement of what can be feasibly achieved by health services. The third recommendation is that in further studies the number of services for which unmet need is measured should be increased to include such services as Pap smears, breast cancer self-detection instructions, and counseling on menstrual irregularities, as well as others that are important from a public health perspective and from the point of view of the clients.

To measure changes in partner dynamics, this project used a set of questions on perceptions of gender roles, communication with partners, sexual and contraceptive practices, and gender-related violence. ${ }^{14}$ This series of questions provides an important contribution to the field of gender research in the context of reproductive and sexual health services and should be applied, validated, and expanded upon in further research.

The results show that the intervention might have made modest but important changes in partner dynamics. Women's confidence in their capacity to talk to their partners on various aspects of sexual and reproductive health increased, as well as their perception that they have the right to use a contraceptive method regardless of what their partner thought. A greater consciousness of the right to sexual enjoyment was also found, as well as the feeling that they could better negotiate this enjoyment with their partner. Moreover, a decrease in tolerance of violence against women by their intimate companions was found.

3) Does the incorporation of a gender perspective into health service delivery have an impact on demand for services?

In this project no evidence was found that the incorporation of a gender perspective had an effect on the demand for sexual and reproductive health services. There was, however, an increase in user satisfaction, and perhaps the lack of increase in demand is a result of lack of time for publicity by these satisfied users to cause considerable impact. The second consideration is that quality in and of itself does not attract new users. To increase demand among clients, it is necessary to have marketing strategies including publicity, affordable prices, and a recognizable place where services are offered. Quality of care is an important aspect of maintaining clients, however; and it can be expected that in the future there will be a noticeable increase in clientele in participating clinics.

${ }^{14}$ Indicators to measure changes in partner dynamics developed by Julie Pulerwitz. 
4) What are the costs of incorporating a gender perspective into reproductive health services?

In this project, the average total cost (financial cost and non-financial cost) per participating clinic of incorporating the gender component was US\$23,148. This amount included an allotment of US\$3,500 to each NGO and PROCOSI support of approximately $\$ 8,000$ per NGO. If these financial contributions are subtracted from the total average cost, the result is that, on average, NGOs used US\$11,646 of their own resources on this project. In the context of the current study, if change in unmet need is posited as the measure of success, then the question for program managers is whether this expenditure is justified to achieve the resulting changes in unmet need. 


\section{REFERENCES}

CIDEM y FHI. 1999. Para conocer y respetar las diferencias y derechos en salud sexual y reproductiva. La Paz, Bolivia; CIDEM y FHI. Esta debe ser considerada la referencia básica para el capítulo.

De Barbieri, Teresita. 1991. Sobre la Categoría de Género. Una introducción teórica metodológica. Direitos Reproductivos, Fundación Carlos Chagas, Sao Paulo.

Weiss, Ellen and G.R. Gupta. 1998. Bridging the Gap. Addressing Gender and Sexuality in HIV Prevention. Washington, D.C., ICRW

Yinger, Nancy with A. Peteron and M. Avni. 1999. Mainstreaming Gender in Monitoring and Evaluation. A Practical Approach form Reproductive Health Programming. Proyecto preparado para IGWG okenbart, October

IPPF/WHR. 2000. Manual para evaluar la calidad de atención desde una Perspectiva de Género. La Paz, Bolivia.

IPPF/WHR. New York, NY; y Reyes Zapata, Hilda et al. 1999. Un sistema de medición de la calidad de los servicios de salud sexual y reproductiva desde una perspectiva de género Documento de Trabajo 29. México, D.F., INOPAL III, Population Council.

Family Care International. Action for the 21 st Century. Reproductive Health \& Rights for All. Reporte sumario de acciones recomendadas y salud reproductiva y derechos, del programa de acción de ICPD de Cairo ICPD, Septiembre 1994. Preparado por María José Alcalá. New York, NY, Family Care International

Younger, E. Wittet, S. Hooks, C y Laser, H. 2001. "Guía para el diseño y elaboración de investigaciones cualitativas" Capítulo. En profundidad, Pág. 19- 36. PATH, Seattle, Washington. USA

Montaño, Ma. Lizzy, Informe final sobre la implementación del Programa de Género ejecutado por PROCOSI - 2001 - 2003. La Paz, Bolivia. 


\section{$X$ APPENDICES}

Appendix 1: List of participating organizations in the PROCOSI Gender Program and FRONTIERS follow-up

Appendix 2: List of IPPF Gender Manual indicators by area

Appendix 3: Workshops organized by the Gender Program

Appendix 4: Geographic distribution of the sample and type of management of participating clinics 


\section{APPENDIX 1}

\section{List of Organizations Participating in PROCOSI's Gender Program and FRONTIERS Follow-Up}

\begin{tabular}{|c|c|c|c|c|c|c|c|c|}
\hline \multirow{3}{*}{$\frac{\mathbf{N}^{\circ}}{1}$} & \multirow{3}{*}{$\begin{array}{l}\text { NGO } \\
\text { APROSAR }\end{array}$} & \multirow{3}{*}{$\begin{array}{l}\text { Department } \\
\text { Oruro }\end{array}$} & \multicolumn{2}{|c|}{ Area } & \multicolumn{2}{|c|}{$\mathbf{N}^{\circ}$ of Clinics } & \multirow{2}{*}{\multicolumn{2}{|c|}{$\begin{array}{l}\text { Participated in } \\
\text { FRONTIERS } \\
\text { Follow-up }\end{array}$}} \\
\hline & & & \multirow{2}{*}{$\frac{\text { Urban }}{x}$} & \multirow{2}{*}{$\frac{\text { Rural }}{x}$} & \multirow{2}{*}{$\frac{\text { O.M. (a) }}{1}$} & \multirow{2}{*}{$\frac{\text { PHS (b) }}{1}$} & & \\
\hline & & & & & & & YES & $x$ \\
\hline 2 & APSAR & Cochabamba & & $x$ & 1 & & YES & $x$ \\
\hline \multirow[t]{2}{*}{3} & CARE & Santa Cruz & & $x$ & & 4 & NO & \\
\hline & & Tarija & & & & 3 & YES & $X$ (one) \\
\hline 4 & CEPAC & Santa Cruz & & $x$ & & $5(c)$ & NO & \\
\hline \multirow[t]{4}{*}{5} & CIES & La Paz & $x$ & & 3 & & NO & \\
\hline & & El Alto & & & & & YES & $x$ \\
\hline & & Oruro & & & & & YES & $\mathrm{X}$ \\
\hline & & Tarija & & & & & NO & \\
\hline 6 & CEMSE & La Paz & $x$ & & 1 & & YES & $x$ \\
\hline \multirow[t]{4}{*}{7} & CRECER & La Paz & $x$ & & & & NO & \\
\hline & & Oruro & & & & & NO & \\
\hline & & Cochabamba & & & & & NO & \\
\hline & & Chuquisaca & & & & & NO & \\
\hline 8 & CRS & Cochabamba & & $x$ & & 1 & YES & $x$ \\
\hline 9 & CSRA & Santa Cruz & $x$ & & 1 & & YES & $x$ \\
\hline 10 & Esperanza & Tarija & $x$ & $x$ & & 3 & NO & \\
\hline 11 & $\mathrm{PCl}$ & Cochabamba & $x$ & & & & NO & \\
\hline \multirow[t]{4}{*}{12} & PRO MUJER & La Paz & $x$ & & 37 & & YES & $X$ (one) \\
\hline & & Cochabamba & & & & & NO & \\
\hline & & Tarija & & & & & NO & \\
\hline & & Chuquisaca & & & & & NO & \\
\hline \multirow[t]{2}{*}{13} & PROSALUD & La Paz & $x$ & & 14 & & YES & $X$ (one) \\
\hline & & El Alto & & & & & NO & \\
\hline 14 & SACOA & Santa Cruz & & $x$ & 5 & & NO & \\
\hline \multirow[t]{2}{*}{15} & SERVIR & La Paz (Caranavi) & $\mathrm{x}$ & $\mathrm{x}$ & & & NO & \\
\hline & & & & & & & NO & \\
\hline 16 & SCC & Cochabamba & $x$ & & & & NO & \\
\hline \multirow[t]{2}{*}{17} & SAVE USA & Oruro & $x$ & & & 2 & NO & \\
\hline & & La Paz & & & & & NO & \\
\hline
\end{tabular}

Source: PROCOSI Gender Program

(a) Services with their own management

(b) Services managed by the state

(c) Mobile health units with CEPAC and Health District staff 


\section{APPENDIX 2}

\section{List of IPPF Gender Manual Indicators}

\begin{tabular}{|c|c|}
\hline \multicolumn{2}{|c|}{ 1. Institutional Policies and Practices } \\
\hline 1.1 & $\begin{array}{l}\text { Existence of a declaration in the institution's mission that promotes women's } \\
\text { empowerment. }\end{array}$ \\
\hline 1.2 & Existence of policies that prohibit gender-based discrimination. \\
\hline 1.3 & $\begin{array}{l}\text { Existence of policies and procedures to ensure gender equality in promotion of } \\
\text { personnel. }\end{array}$ \\
\hline 1.4 & Existence of policies that prohibit the abuse of power in the institution. \\
\hline 1.5 & Percentage of management/executive positions assigned to women. \\
\hline 1.6 & $\begin{array}{l}\text { Percentage of managing positions with budgetary responsibility assigned to } \\
\text { women. }\end{array}$ \\
\hline 1.7 & Percentage of positions with higher salaries assigned to women. \\
\hline 1.8 & $\begin{array}{l}\text { Percentage of personnel that feels the institution's executives are receptive to their } \\
\text { opinions and suggestions. }\end{array}$ \\
\hline 1.9 & Percentage of recommendations made by providers that have been implemented \\
\hline 1.10 & Percentage of personnel that feels motivated to offer opinions/suggestions. \\
\hline 1.11 & $\begin{array}{l}\text { Percentage of personnel that feels the institution has a collective and teamwork } \\
\text { environment. }\end{array}$ \\
\hline 1.12 & $\begin{array}{l}\text { Percentage of providers that feel that the institution is receptive to explanations for } \\
\text { leaving work when required by family reasons. }\end{array}$ \\
\hline 1.13 & $\begin{array}{l}\text { Percentage of personnel that feels the institution gives preferential treatment to a } \\
\text { particular sex. }\end{array}$ \\
\hline 1.14 & $\begin{array}{l}\text { Existence of policies or protocols that specify taking into account gender conditions } \\
\text { for service delivery. }\end{array}$ \\
\hline 1.15 & Percentage participation by women, men, and couples in RHS visits. \\
\hline 1.16 & Office hours established with a basis on gender needs. \\
\hline 1.17 & Existence of counseling services as institutional policy. \\
\hline 1.18 & Existence of services that require the husband's consent. \\
\hline 1.19 & $\begin{array}{l}\text { Existence of a range of contraceptive methods according to norms established by } \\
\text { the } \mathrm{MOH} / \text { institution/ }\end{array}$ \\
\hline \multicolumn{2}{|c|}{ 2. Provider practices } \\
\hline 2.1 & Percentage of clients greeted. \\
\hline 2.2 & Percentage of clients who are told the name of the provider attending to them. \\
\hline 2.3 & Percentage of clients called by their first or last name. \\
\hline 2.4 & Percentage of clients that are treated with diminutives. \\
\hline 2.5 & $\begin{array}{l}\text { Percentage of visits/counseling sessions in which the service provider explores } \\
\text { sexual and reproductive health topics. }\end{array}$ \\
\hline 2.6 & $\begin{array}{l}\text { Percentage of visits/counseling sessions in which the provider explores aspects } \\
\text { related to the client's sexual health. }\end{array}$ \\
\hline 2.7 & ercentage of providers that feel that RHS topics are not explored due to barri \\
\hline
\end{tabular}

Effects and Cost of Implementing a "Gender-Sensitive" Reproductive Health Program 


\begin{tabular}{|c|c|}
\hline 2.8 & $\begin{array}{l}\text { Percentage of visits/counseling sessions in which the service provider used } \\
\text { didactic material (drawings, pamphlets, flip-chart or other material) to reinforce } \\
\text { explanations. }\end{array}$ \\
\hline 2.9 & $\begin{array}{l}\text { Percentage of visits/counseling sessions in which the service provider } \\
\text { communicated with the client through simple language. }\end{array}$ \\
\hline 2.10 & $\begin{array}{l}\text { Percentage of visits/counseling sessions in which the service provider explained } \\
\text { the details of the diagnosis. }\end{array}$ \\
\hline 2.11 & $\begin{array}{l}\text { Percentage of visits/counseling sessions in which the service provider explained } \\
\text { treatment details to the client. }\end{array}$ \\
\hline 2.12 & $\begin{array}{l}\text { Percentage of visits/counseling sessions in which the service provider looked } \\
\text { directly at the client while explaining the diagnosis or treatment. }\end{array}$ \\
\hline 2.13 & $\begin{array}{l}\text { Percentage of visits/counseling sessions in which the service provider asked the } \\
\text { client if she had questions or doubts. }\end{array}$ \\
\hline 2.14 & $\begin{array}{l}\text { Percentage of visits/counseling sessions in which the service provider answered } \\
\text { questions or cleared client's doubts. }\end{array}$ \\
\hline 2.15 & $\begin{array}{l}\text { Percentage of visits in which the service provider explained what she/he was doing } \\
\text { during the pelvic exam. }\end{array}$ \\
\hline 2.16 & $\begin{array}{l}\text { Percentage of visits/counseling sessions in which the service provider provided } \\
\text { information or educational materials (pamphlets, leaflets, or others) for the client to } \\
\text { take home. }\end{array}$ \\
\hline 2.17 & $\begin{array}{l}\text { Percentage of providers that know the lapse of time from the client's arrival until } \\
\text { she is attended by the doctor. }\end{array}$ \\
\hline 2.18 & Average waiting time experienced by clients. \\
\hline 2.19 & $\begin{array}{l}\text { Percentage of personnel who know the definition of reproductive and sexual } \\
\text { health. }\end{array}$ \\
\hline 2.20 & $\begin{array}{l}\text { Percentage of personnel that can identify the sexual and reproductive health } \\
\text { services offered by the institution. }\end{array}$ \\
\hline 2.21 & $\begin{array}{l}\text { Percentage of clinical histories where RHS-related topics were dealt with, } \\
\text { including: sexuality, violence and other abuses of power, sexually transmitted } \\
\text { infections, condom use, and partner negotiation. }\end{array}$ \\
\hline 2.22 & $\begin{array}{l}\text { Percentage of visits/counseling sessions in which the service provider dedicated } \\
\text { all his/her time to the client without interruptions. }\end{array}$ \\
\hline 2.23 & Percentage of personnel who know and promote the use of dual protection. \\
\hline 2.24 & Percentage of personnel that knows and promotes Pap smears. \\
\hline 2.25 & Percentage of personnel who know and promote breast self-examination. \\
\hline \multicolumn{2}{|c|}{ 3. Client comfort } \\
\hline 3.1 & Percentage of women who find office hours convenient. \\
\hline 3.2 & Percentage of clients who have difficulties in coming to the service. \\
\hline 3.3 & Existence of resources to attend and entertain children in health service outlet. \\
\hline 3.4 & Existence of a physical space for childcare in the service outlet. \\
\hline \multicolumn{2}{|c|}{ 4. Client satisfaction } \\
\hline 4.1 & $\begin{array}{l}\text { Existence of mechanisms to collect the opinions of clients on office hours and } \\
\text { general client satisfaction. }\end{array}$ \\
\hline 4.2 & Satisfactory infrastructure conditions. \\
\hline 4.3 & Equipment available and in good state. \\
\hline 4.4 & $\begin{array}{l}\text { Existence of conditions to ensure confidentiality, privacy, and peace of mind of } \\
\text { client. }\end{array}$ \\
\hline 4.5 & Enough seats for clients in waiting area. \\
\hline 4.6 & Percentage of clients that report general satisfaction with the services received. \\
\hline
\end{tabular}

Effects and Cost of Implementing a "Gender-Sensitive" Reproductive Health Program 


\begin{tabular}{|c|l|}
\hline 4.7 & $\begin{array}{l}\text { Percentage of clients that feel comfortable with the conversation, with asking } \\
\text { questions, and clearing up doubts with providers. }\end{array}$ \\
\hline 4.8 & Percentage of clients that report that time with service provider was sufficient. \\
\hline 4.9 & $\begin{array}{l}\text { Percentage of clients that report having received good treatment from the outlet } \\
\text { staff. }\end{array}$ \\
\hline 4.10 & $\begin{array}{l}\text { Correspondence between clients who prefer being attended by a man or a woman } \\
\text { and the gender of the provider who attended to them. }\end{array}$ \\
\hline $\mathbf{5 . ~ U s e ~ o f ~ g e n d e r e d ~ l a n g u a g e ~}$ \\
\hline 5.1 & Use of non-discriminatory language. \\
\hline 5.2 & Use of inclusive language. \\
\hline $\mathbf{6 . ~ I n f o r m a t i o n , ~ e d u c a t i o n , ~ c o m m u n i c a t i o n , ~ a n d ~ t r a i n i n g ~}$ \\
\hline 6.1 & $\begin{array}{l}\text { Existence of IEC and training material with information on sexual and reproductive } \\
\text { rights (including women's rights). }\end{array}$ \\
\hline 6.2 & $\begin{array}{l}\text { Existence of IEC and training materials with information on sexual and } \\
\text { reproductive health. }\end{array}$ \\
\hline 6.3 & Visual and/or accessible information on the health outlet. \\
\hline 6.4 & Development of educational activities for clients in waiting area. \\
\hline 6.5 & Activities demanded by clients as they wait. \\
\hline 7. Monitoring and evaluation \\
\hline 7.1 & $\begin{array}{l}\text { Existence of a mechanism to establish programmatic changes on the basis of } \\
\text { information obtained from clients. }\end{array}$ \\
\hline
\end{tabular}

Effects and Cost of Implementing a "Gender-Sensitive" Reproductive Health Program 


\section{APPENDIX 3}

\section{Workshops Organized by the Gender Program}

\begin{tabular}{|c|c|c|c|c|}
\hline Workshop & Facilitator & Level & $\begin{array}{l}\text { No. of } \\
\text { work- } \\
\text { shops }\end{array}$ & $\begin{array}{l}\text { No of } \\
\text { partici- } \\
\text { pants }\end{array}$ \\
\hline $\begin{array}{l}\text { "Sensitizing on gender and training on } \\
\text { the Manual to Evaluate Quality of } \\
\text { Care from a Gender Perspective" }\end{array}$ & $\begin{array}{l}\text { REPROSALUD/MMR } \\
\text { IPPF/RHO Bolivia }\end{array}$ & National & 1 & 46 \\
\hline $\begin{array}{l}\text { "Training in instruments for building a } \\
\text { baseline" }\end{array}$ & IPPF/RHO Bolivia & Regional & 5 & 69 \\
\hline "Preparing baseline results" & Frontiers Project/Population Council & Regional & 3 & 44 \\
\hline $\begin{array}{l}\text { "Gender perspective in creating IEC } \\
\text { material" }\end{array}$ & REPROSALUD/MMR & National & 1 & 31 \\
\hline "Labor and gender rights" & Coordinadora de la Mujer & National & 1 & 37 \\
\hline $\begin{array}{l}\text { "Recognizing and respecting sexual } \\
\text { and reproductive differences and } \\
\text { rights" }\end{array}$ & Independent consultants & Institutional & 17 & 360 \\
\hline $\begin{array}{l}\text { "Sensitizing on sexuality with a focus } \\
\text { on gender and rights" }\end{array}$ & Independent consultant & Institutional & 18 & 271 \\
\hline $\begin{array}{l}\text { "Missed opportunities and systematic } \\
\text { supply of RHS" }\end{array}$ & Frontiers Project/Population Council & Regional & 2 & 49 \\
\hline $\begin{array}{l}\text { "Training in the use of databases for } \\
\text { gender" }\end{array}$ & Independent consultant & National & 1 & 16 \\
\hline $\begin{array}{l}\text { "Prevention and care of cases of } \\
\text { family violence for health personnel" }\end{array}$ & $\begin{array}{l}\text { Ministerio de Salud y Previsión Social } \\
\text { OPS/OMS }\end{array}$ & National & 1 & 30 \\
\hline $\begin{array}{l}\text { "Denouncing violence through its } \\
\text { critical path" }\end{array}$ & $\begin{array}{l}\text { Centro de Promoción de la Mujer } \\
\text { Gregoria Apaza }\end{array}$ & Institutional & 18 & 526 \\
\hline $\begin{array}{l}\text { "Institutionalization of a gender focus } \\
\text { in programs and projects" }\end{array}$ & Independent consultant & National & 1 & 26 \\
\hline $\begin{array}{l}\text { "Improvement of quality of service } \\
\text { from a gender perspective: lessons } \\
\text { learned from the PROCOSI network" }\end{array}$ & Gender Program Coordinator & National & 1 & 42 \\
\hline & & & TOTAL & 1,547 \\
\hline
\end{tabular}

Effects and Cost of Implementing a "Gender-Sensitive" Reproductive Health Program 


\section{APPENDIX 4}

\section{Geographic distribution of the sample and type of management of}

participating clinics

\begin{tabular}{|c|c|c|c|c|c|}
\hline $\mathbf{N}^{\circ}$ & DEPARTMENT & AREA & $\begin{array}{l}\text { CITY OR } \\
\text { LOCATION }\end{array}$ & NGO & TOTAL NGOs \\
\hline \multirow[t]{2}{*}{1} & \multirow[t]{2}{*}{ La Paz } & Urban & City of La Paz & $\begin{array}{c}\text { CEMSE } \\
\text { PROSALUD }\end{array}$ & 2 \\
\hline & & Peri-urban & City of El Alto & $\begin{array}{c}\text { CIES } \\
\text { PROMUJER }\end{array}$ & 2 \\
\hline \multirow[t]{2}{*}{2} & \multirow[t]{2}{*}{ Oruro } & Urban & City of Oruro & CIES & 1 \\
\hline & & Rural & Huanuni & APROSAR & 1 \\
\hline \multirow[t]{2}{*}{3} & \multirow[t]{2}{*}{ Cochabamba } & \multirow[t]{2}{*}{ Rural } & Totora & CRS & 1 \\
\hline & & & Mallco Rancho & APSAR & 1 \\
\hline 4 & Santa Cruz & Peri-urban & Montero & CSRA & 1 \\
\hline 5 & Tarija & Peri-urban & Bermejo & CARE & 1 \\
\hline \multicolumn{5}{|c|}{ TOTAL } & 10 \\
\hline
\end{tabular}

Source: Research "Effects and Costs" 